\title{
El problema del concepto de la culpa en la lex Aquilia: Una mirada funcional
}

\author{
Cristián Aedo Barrena*
}

\begin{abstract}
RESUMEN
El presente artículo persigue analizar las distintas posiciones que en la romanística moderna se han elaborado en relación con el concepto de la culpa y su papel en el régimen del delito aquiliano. Destacaremos tres posiciones: aquella que concibe la culpa como un producto de la época justinianea, entendiendo que la culpa equivalía a la imputabilidad o la mera relación causal en el período clásico; otra, por el contrario, sostiene que la culpa, en el período clásico, correspondía a la negligencia, entendida como la desviación del estándar del buen padre de familia. Según una tercera teoría, tanto en el período clásico como posteriormente, la culpa expresaba la conducta que podía ser considerada como una materia de reproche individual. En una segunda parte del artículo, se expondrá la crítica metodológica, especialmente a la aplicación de las categorías responsabilidad objetiva-subjetiva para el Derecho romano. Por último, se propone analizar el concepto de la culpa a la luz de sus relaciones con la causalidad, lo que permite descartar la tesis objetiva.
\end{abstract}

Culpa - iniuria - relación de causalidad - lex Aquilia

\section{The problem of the concept of the blame on lex Aquilia: A functional perspective}

\begin{abstract}
'This article analyses the different theories in modern Roman law studies that have been developed to understand the concept of culpa and its role in the scheme of tortious liability. Three positions are highlighted: the first sees the notion of culpa as a result of the Justinian era, under the basis that it tantamount to mere causal relation in the classical period; the second, in contrast, argues that culpa, during the classical period, corresponded to negligence, and is defined as the deviation from the good father's standard. According to a third theory, both in the classical period and later, culpa expressed a behaviour that could be considered a matter of individual condemnation. The second part of the article discusses the methodological aspects of these positions, especially of the application of strict liability and negligence-based liability to the categories of Roman law. Finally, the concept of culpa is analysed in light of its relations with causality, discarding the strict liability thesis.
\end{abstract}

$$
\text { Culpa - iniuria - causal relation - lex Aquilia }
$$

* Profesor de Derecho Universidad Católica del Norte. Doctor en Derecho Universidad de Deusto, España. Correo caedo@ucn.cl

Artículo recibido el 30 de agosto de 2013 y aceptado para para su publicación por el Comité Editorial el 28 de mayo de 2014 . 


\section{Introducción: LA CULPA EN EL CONTEXTo DE LA LEX AQUiLIA}

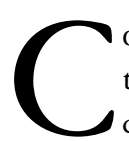

omo indica Albanese, la obra jurisprudencial fue particularmente incisiva sobre todo en orden a cuatro perfiles en relación con los capítulos primero y tercero de la ley: a) superación de los límites impuestos por los verbos usados para describir la actividad dañosa: occidere, en el capítulo primero; urere, frangere, rumpere, en el tercero; b) desarrollo de una vasta perspectiva de responsabilidad, predicada en términos de iniuria hasta la refinada perspectiva de la culpa; c) paso de una aestimatio fundada sobre el precio de mercado del objeto del daño y de una valoración coincidente, a veces, con el interés subjetivo del dañado; d) extensión del resarcimiento del daño a sujetos distintos del propietario ${ }^{1}$.

El delito de damnum, regulado en el plebiscito aquiliano, no contempló como criterio de determinación del delito, la culpa. Esta cualificaba la conducta mediante la herramienta de la iniuria (técnicamente, acto sine iure). La culpa surge como herramienta de interpretación que vino a corregir los problemas presentados por la iniuria, en toda una gama de casos, en los que, a pesar de ser lícita la conducta, había un potencial dañoso. En definitiva, la iniuria -que importaba originariamente una conducta cualificada que autorizaba a inferir menoscabo a otro en defensa de la propiedad-, fue posteriormente reemplazada por la culpa, durante el período clásico. Algunos textos que muestran esta evolución serían los del D. 9, 2, 52, 1 y 52, 4, así como D. 9, 2, 5, $3^{2}$.

$\mathrm{Y}$, con independencia de esta consideración, los autores concuerdan en que esta cumplió otros papeles, que excedían el ámbito de aplicación de la iniuria. En primer término, la culpa habría sido utilizada para restringir el ámbito de aplicación de la iniuria, entendida esta como ilegalidad o antijuridicidad. A pesar de la ilegalidad del acto, este podría ser excusado en casos de no existir intención o simple negligencia ${ }^{3}$. Además, según Beinart, la culpa (como culpabilidad) habría desempeñado un tercer rol, opuesto al anterior, en el entendido que habría sido utilizada para ampliar el rango o campo de la responsabilidad, en supuestos en los que, no obstante encontrarnos en presencia de

\footnotetext{
${ }^{1}$ Albanese, B., "Recensioni critiche a Valditara. Superamento dell'aestimatio rei nella valutazione del danno aquiliano ed estensione della tutela ai non domini”, en IURA 43, 1992, p. 244.

${ }^{2}$ Beinart, B., "The relationship of iniuria and culpa in the lex Aquilia", en AA.VV. Studi in onore di Vicenzo Arangio-Ruiz, Jovene Editore, Napoli, 1964, pp. 286-289.

${ }^{3}$ En este sentido, Beinart, cit., pp. 285-286. Zimmermann, R., The Law of Obligations. Roman Foundations of the Civilian Tradition, Oxford, 1996, p. 1005, explica que hubo casos en los que no podía decirse que el autor había actuado iure, pero en los cuales resultaba irracional imponer la poena derivada del delito. Cita algunas decisiones, como el pasaje del D. 9, 2, 30, 3, en el que si alguien prendía fuego a su rastrojo o zarzal para quemarlo y este se expandía, causando daño a su vecino, la imposición de responsabilidad solo se hacía efectiva en el supuesto de existencia de una falta de control o cuidado para evitar el daño, es decir, en un supuesto de culpa, con independencia de la iniuria. Agrega que este tipo de casos debió haberse presentado cada vez más a menudo, en la medida que la interpretación de los verbos fue ampliándose por las acciones decretales.
} 
una conducta ajustada a Derecho, el demandado debía responder, sin embargo, por el delito de daños ${ }^{4}$.

Como fuere, según estas tesis, con sus variaciones, es claro que la iniuria terminó evolucionando hacia la culpa, de modo que ambos conceptos pasaron a ser equivalentes. En lo que no hay completo acuerdo es desde cuándo ocurrió este cambio. Por eso se debate en torno al momento en el que se produjo la subjetivación de la iniuria y su evolución hacia la culpa. Pueden destacarse, según pensamos, tres posturas: la tradicional entiende que fueron los veteres los que introdujeron consideraciones subjetivas, asimilando la iniuria a la culpa. Otra, según la cual la culpa se debió al desarrollo de los clásicos y una tercera corriente entiende que aun los juristas clásicos analizaron la cuestión con un prisma objetivo, produciéndose el cambio durante el bajo imperio.

La primera tesis, que según Perrin es la tradicional, considera que el cambio hacia una culpa operó en la época de los veteres y en particular se debió a Quinto Mucio, con su célebre definición de la culpa aquiliana, en el también famoso caso del podador, en D. 9, 2, 31 pr. Para Perrin, durante el siglo I d.C. el pensamiento filosófico se preocupó de fundamentar la intencionalidad de la responsabilidad delictual, agregando que el defecto de todo elemento intencional, que provenía desde el esquema de las XII Tablas, debió haber sido considerado una monstruosidad jurídica. Agrega: Tout à la fois progressistes et conservateurs, les veteres n'auraient $p u-n i$ voulu-y introduire l'exigence du dol qu'exclut le texte même de la loi et qui en ê̂t modifié complètement l'economie. S'en tenant à l'iniuria, ils ent anaurient dégagé, par une analyse extensive dl'acte accompli sans droit, une notion intermédiaire, susceptible d'éliminer le cas fortuit et la force majeure.

\footnotetext{
${ }^{4}$ Beinart, cit., pp. 289-292. Coincide especialmente con este punto de vista Cannata, C.A., Per lo studio della responsabilità per colpa nel diritto romano classico, La Giolardica, Milano, 1969, pp. 308-309, quien indica que en toda una gama de comportamientos lícitos o debidos de un sujeto que causaba daños, la jurisprudencia comenzó a indagar la culpa para afirmar la responsabilidad, más allá de la circunstancia de ser conducido a un juicio de licitud. Un cambio de este tipo también lo sitúa en el pasaje del D. 9, 2, 31 pr. En la misma línea, Zimmermann, cit., p. 1006, quien como vimos precedentemente entiende que hubo una especie de evolución paulatina de la mano con la ampliación pretoria de la acción directa, comenzando por aquellos supuestos en los que no resultaba razonable imponer responsabilidad, al no existir culpa, a pesar de no poder calificar el comportamiento como iure, pasando por los casos en los que, a pesar de existir conducta iure, se obliga a responder hasta la equiparación definitiva iniuria y culpa, o, más bien, el reemplazo de la segunda por la primera.

${ }^{5}$ Perrin, B., "Le caractère subjectif de l'iniuria aquilienne à l'époque classique", en Edoardo Volterra (a cura di), Studi in onore di Pietro de Francisci, Guiffrè, Milano, 1956, vol. IV, pp. 268-270. En un sentido similar puede consultarse a Talamanca, M., Istituzioni di Diritto Romano, Giuffrè, Milano, 1990, p. 627, quien explica que el dañante respondía en un principio solo por el simple nexo de causalidad, indicando que el término culpa, empleado a propósito del daño, había tenido solo este significado, hasta el inicio del siglo I a.C., cuando Q. Mucio afirmó que la culpa consistía en no prever lo que una persona diligente debió haber previsto, en el pasaje del D. 9, 2, 31 pr, de modo que la responsabilidad aquiliana pasó de ser objetiva a una subjetiva, a título de dolo y culpa. En similares términos se pronuncian, entre otros, Pugsley, D., "On the lex Aquilia and culpa", en TR 50, 1982, pp. 11-13. También Visky, K., "La responsabilité dans le droit romain á la fin de la République", en AA.VV., Mélanges Fernand de Visscher, RIDA, Bruselas, 1949, t. II, pp. 448460; 480, indica que al final de época republicana se introduce la culpa como criterio de responsabilidad, con dos significados: como conducta reprobable en general, es decir, como culpabilidad, comprendiendo el dolo; y, en un sentido estricto, la negligencia, como grado de responsabilidad contraria al dolo. Cannata, Per lo studio..., cit., pp. 304-305 también atribuye a los autores republicanos el tránsito de la iniuria a la culpa.
} 
Algunos autores, no obstante, se inclinan por estimar que fue la jurisprudencia clásica la que introdujo y desarrolló la sanción de las conductas negligentes, por medio de la palabra culpa. Son significativamente claras las palabras de d'Ors, quien estima que a diferencia de otros delitos, la primera jurisprudencia clásica interpretó la palabra iniuria en el sentido que debía responderse también de ciertos actos de negligencia ${ }^{6}$.

La tercera tesis ha sido defendida fundamentalmente por Arangio-Ruiz, quien entiende que la culpa corresponde a un desarrollo del Bajo Imperio. Según este autor, la culpa, incluso en el período clásico, fue entendida como la relación de causalidad entre el autor y el daño causado. Profundizaremos en estas opiniones al analizar el concepto de la culpa ${ }^{7}$. Para Guarino, fue la jurisprudencia postclásica justinianea, o, al menos la tardoclásica, la que introdujo el concepto de dolo como intencionalidad del evento dañoso y la culpa como simple voluntariedad no intencional del acto ilícito, así como la distinción entre negligencia, imprudencia, impericia y los grados de culpa ${ }^{8}$.

Ahora bien, contrariamente a lo que se afirma a menudo, especialmente en la dogmática civil, en relación con el concepto de la culpa, ha existido una profunda discusión en la romanística moderna. Siguiendo a MacCormack, se han elaborado tres corrientes en relación con el concepto de la culpa. Según él, estas tres corrientes pueden ser agrupadas de la siguiente forma: a) la culpa entendida como negligencia, es decir, la falta de cuidado de un buen padre de familia, siendo este significado tanto en el Derecho clásico como en el tardío; b) entender que en el Derecho clásico, la culpa expresaba solo la conexión causal entre el acto dañoso y la persona que lo cometió, siendo el concepto de la negligencia un producto de la jurisprudencia tardía; c) que durante el Derecho clásico, como el tardío, la culpa fue entendida como una conducta que podía ser considerada como materia de reproche hacia un sujeto ${ }^{9}$. Analicemos cada una de ellas.

${ }^{6}$ D’Ors, A., Derecho Privado Romano, Ediciones Universidad de Navarra, 9a edición, Pamplona, 1997, p. 436. Gran parte de las obras generales, con alguna menor o mayor diferencia, se inclinan por pensar que dicho cambio se produjo definitivamente durante el período clásico. Así, por ejemplo, Volterra, E., Instituciones de Derecho Privado Romano, trad. de Jesús Daza Martínez, Civitas, reimpresión $1^{a}$ edición, Madrid, 1988 , p. 561 considera que la introducción del dolo y la culpa se produce durante el siglo II d.C. y en igual sentido, Pugliese, G., Istituzioni di Diritto Romano, Giappichelli, $3^{\text {a }}$ edición, Torino, 1991, pp. 606-607. En el ámbito anglosajón, muy claramente desde este punto de vista, aunque situando la evolución en el siglo I a.C., entre los juristas tardorrepublicanos y los juristas clásicos como Pomponio, Paulo y Quinto Mucio, Watson, A., Roman Private Law around 200 B.C., Edinburgh University Press, Edinburgh, s.d., pp. 153-154; Watson, A., The law of obligations in the later Roman Republic, Clarendon Press, London, 1965, pp. 246 y ss.

${ }^{7}$ Arangio-Ruiz, V., Responsabilità conttratuale in Diritto romano, Editricce Eugenio Jovene, reimpresión $2^{a}$ edición, Napoli, 1958 , pp. 225 y ss.

${ }^{8}$ Guarino, A., Diritto Privato Romano, Editore Jovene, Napoli, 1997, pp. 1024-1025. En este sentido, también, Bonfante, P., Instituciones de Derecho Romano, trad. de la $8^{\text {a }}$ edición italiana por Luis Bacci y Andrés Larrosa, revisada por Fernando Campuzano Horma, Reus, $2^{\text {a }}$ edición, Madrid, 1959, p. 532.

${ }^{9}$ MacCormack, G., "Aquilian culpa”, en Alan Watson (editor), Daube Noster. Essays in Legal History for David Daube, Scottisch Academic Press, Edinburgh, 1974, p. 202. Esta misma sistematización había sido ofrecida antes por el autor, en Mac Cormack, G., "Culpa”, en SDHI 38, 1972, pp. 123-129, agregando que todas ellas parecen tener apoyo en las fuentes, aunque como veremos luego, considera que el concepto más adecuado para la culpa fue el más amplio de falta. 


\section{EL CONCEPTO DE LA CULPA: LAS DISTINTAS POSICIONES}

\section{A. La tesis objetivista: la culpa como mera imputabilidad o equivalente al nexo de causalidad}

Hechas estas precisiones previas, comenzaremos por aquella que reduce el papel de la culpa al mero nexo causal, o bien que considera que la iniuria solo envolvía imputabilidad; la culpa, como criterio de imputación de responsabilidad, por el contrario, sería solo un fruto del desarrollo justinianeo. Hay, por tanto, en esta corriente, dos líneas diversas que tienen una aparente simetría: considerar la culpa propia de una época muy tardía. Pero a partir de ahí, los matices son profundos. Podemos explicar las distintas perspectivas de los autores por capas, desde aquellos que admiten bases de la idea de culpa en el período clásico hasta los que entienden que culpa fue estrictamente equivalente a la causalidad. Veamos.

Una primera perspectiva pertenece a Betti. Para este autor es un error considerar la responsabilidad derivada de la lex Aquilia como objetiva, para ponerla en antítesis con la época justinianea, en que se erige la culpa como criterio de responsabilidad, entendida como la falla de la diligencia. En este sentido, Betti cree que la iniuria, como acto sine iure, siempre envolvió la capacidad de discernimiento, concretamente, la conciencia del acto ilícito inferido, no limitándose por tanto la ley al establecimiento de la simple relación de causalidad física. Con todo, está de acuerdo en que la culpa fue exclusivo fruto de la época justinianea ${ }^{10}$.

Un segundo grupo considera que la culpa, de existir, solo se limitaba a un presupuesto elemental de imputabilidad, tesis defendida principalmente por Rotondi, quien basa todo su trabajo en las diferencias que se habrían producido en el régimen de responsabilidad aquiliana consagrado en la ley, hasta su desarrollo clásico y las alteraciones que posteriormente fueron fruto del trabajo justinianeo. A las transformaciones en el aspecto objetivo sucedieron otras en el ámbito subjetivo, que son las que de momento nos preocupan. Comienza por destacar que la culpa no se encontraba prevista originariamente en el texto de la ley, la que se refería exclusivamente al damnum iniuria datum. Se trataba de un elemento objetivo, el daño, cualificado por la iniuria, entendida originariamente en la lex como acción antijurídica, acto de injusticia.

Luego, al no estar presente la culpa como elemento de la lex, los juristas clásicos solo se preocuparon de establecer un mínimo psíquico para la atribución del hecho, mínimo suficiente para reconocer la consecuencia dañosa de un hecho. Y este sería el sentido objetivo en el que hablaron los autores de culpa, como en la utilización de Quinto Mucio en D. 9, 2, 31pr. De este modo, los clásicos no desarrollaron la culpa en sentido técnico, como desviación de un estándar de conducta. Un argumento que utiliza el autor para sostener su tesis es que la lex originariamente exigía una conducta corpore corpori. Ello implica que, siguiendo el pasaje D. 7, 1, 13, 2, en la lex Aquilia se

${ }^{10}$ Betti, E., Istituzioni di Diritto Romano, Cedam, Padova, 1962, pp. 310-312. Véase también, Burdese, A., Manuale di Diritto Privato Romano, UTET, $4^{\mathrm{a}}$ edición, Torino, 1993, p. 531, estima que solo la culpa correspondió al desarrollo de la República tardía, pues la iniuria importaba desde un principio la idea de dolo. 
sancionaron solo conductas comisivas, mientras que la consagración de la culpa suponía arribar a una responsabilidad por omisión ${ }^{11,12}$.

Finalmente, desde el ángulo procesal, la introducción de la culpa en sentido técnico también habría sido inocua, pues a diferencia del Derecho moderno, el demandante no debía acreditar la culpa, ni el demandado excluirla. Por el contrario, el demandante debía demostrar la lesión a un derecho propio, en cuanto consecuencia imputable al dañante, mientras que el demandado solo podía liberarse demostrando o la ausencia de iniuria, al encontrarse permitida la conducta o bien demostrando la ausencia de un nexo de causalidad. Concluye sosteniendo que la culpa en sentido técnico fue obra de los compiladores, no en cuanto introdujeran el término, conocido por los clásicos, sino por el contenido, referido a la desviación de un patrón de conducta ${ }^{13}$.

Un paso más extremo se advertirá en Arangio-Ruiz, quien reduce la culpa al mero nexo de causalidad. En principio, señala que la culpa no se encontraba ni en el edicto, ni en la ley, durante la época republicana. En esto, repetimos, hay acuerdo en los autores, de modo que indudablemente se trata de un término introducido por la jurisprudencia, entendida esta por oposición a las fuentes formales del Derecho. Sostiene que los juristas utilizaron la palabra en su sentido común u ordinario y que ella quería decir, al menos en muchos casos, la relación causal que une una conducta con un evento dañoso. Cita varios ejemplos en los que se utilizaría la culpa en este sentido, entre ellos, como máxima general, el pasaje atribuido a Pomponio, en D. 50, 17, 203: Quod quis ex culpa

${ }^{11}$ Rotondi, G., "Dalla 'Lex Aquilia' all art. 1151 Cod. Civ. Ricerche storico-dogmatiche”, en Rivista del Diritto Commerciale, vol. XIV, 1916, pp. 953-957. Véase, en idéntico sentido, Bonfante, cit., p. 532.

${ }^{12}$ La utilización del último argumento es bastante dudoso, porque como ha quedado claro en el desarrollo de la dogmática, tanto civil, como penal, la comisión y la omisión son cuestiones que atañen a la conducta y no a la culpa. Las formas en las que se despliega la manifestación de voluntad de un sujeto corresponden a una categoría enteramente distinta a la culpabilidad del agente al momento de realizar un acto ilícito. Es respecto del acto que se predica tanto la omisión, tanto la culpabilidad de un agente, de modo que es su manifestación en el mundo externo la que puede ser de las formas antes descritas.

Que la negligencia se entienda regularmente como la omisión en los deberes de cuidado no la transforma en la manifestación de voluntad denominada omisión simple o comisiva. En el ámbito penal Rodríguez Devesa, J.M., Derecho Penal. Parte General, Dykinson, 16a edición, Madrid, 1990, p. 300 señala, con certeza, que el que en todo delito culposo tenga que darse una "omisión" de la debida diligencia no quiere decir que todo delito culposo sea un delito de omisión propia o impropia (...) Pues la falta de diligencia puede llevar a un sujeto, lo mismo a realizar un acto que deba omitir, que a omitir un acto que deba realizar. Y agrega: el que por no frenar a tiempo causa la muerte de un transeúnte matándole, causa la muerte por un hacer positivo. El que por no poner señales adecuadas que adviertan del peligro en una zanja que tiene el encargado de vigilar o señalizar da lugar a que por la oscuridad caiga una persona en ella y se lesione, ha cometido un delito... por omisión (comisión por omisión).

Autores que se refieren a la cuestión en el Derecho romano también opinan en igual sentido. Entre ellos, Voci, P., "Diligentia”, "Custodia”, "Culpa”, "I dati fundamentali”, en SDHI 56, 1990, p. 47, quien defiende la tesis opuesta, señala que: Il comportamento negligente può consistere sia in un facere che in un non facere: l'esempio che viene ripetuto è quello dello schiavo cui non si sono prestate le debite cure. También Buckland, W. W, The main institutions of Roman private law, Cambridge University Press, London, 1931, cit., p. 333.

${ }^{13}$ Rotondi, cit., vol. XIV, p. 958. 
sua damnum sentit, non intelligitur damnum sentiré (No se entiende que el que sufre daño por su culpa sufre daño $)^{14}$.

En otras ocasiones la palabra culpa se utilizaba en relación con el problema del delito, pero para indicar la antijuridicidad, particularmente en los delitos públicos y pone como ejemplo el pasaje de Paulo en D. 49, 16, 14, 1, e incluso en un supuesto de delito privado, poniendo como ejemplo el texto del D. 38, 2, 24. Los textos citados, entre otros, le permiten concluir que tanto en materia criminal como en el campo del ilícito privado, el concepto de una responsabilidad por culpa, distinta de aquella por dolo derivada de una falta de voluntad directa a la violación del bien jurídico de otro, surge muy tarde. Primitivamente, incluso en el pensamiento jurídico y filosófico griego, la palabra no se distinguiría del caso fortuito. En la regulación romana primitiva solo se advierte la existencia del dolo para algunos delitos, pero no se menciona la culpa. Ahora bien, si bien reconoce que en época clásica se fue elaborando la expresión culpa se utilizó de manera sumamente restringida, oponiendo el dolo al casus, como lo demostrarían algunos ejemplos. Cita como apoyo de sus argumentos algunos pasajes, entre ellos los textos del D. 48, 8, 1, 3 y 48, 19, 11, $2^{15}$.

Estima el autor que todas estas consideraciones anteriores son trasladables a la lex Aquilia. En principio, el dolo estaba presente originariamente en la sanción de la ley y señala que otros autores lo rechazan al no aparecer la expresión "dolo malo", pero en su concepto otro elemento subjetivo no se deriva de la palabra iniuria. Aunque fuera falaz una conexión entre la iniuria del delito de damnum y de las XII Tablas, como lesión personal, es claro que el ablativo puede haberse incluido con el solo fin de excluir la aplicación de la pena cuando la muerte era causada iure, como en el campo de la legítima defensa u otra acción permitida. Solo en época posterior, por razones de exigencia práctica, fue elaborado por la jurisprudencia el principio de la punibilidad del daño aquiliano causado con culpa; de modo que ahora iniuria pasó a considerarse exactamente como la antítesis de iure, pero se hicieron esfuerzos de interpretación necesarios para considerar que la palabra iniuria incluía el elemento subjetivo del delito. Esta equivalencia entre culpa e iniuria quedaría clara en los textos gayanos 3, 202 y especialmente 3, 211, pero la cuestión que comienza a analizar luego es el papel que la palabra jugó en la jurisprudencia. En este sentido, la exigencia de un daño corpore corpori indicaría que solo sería admisible una culpa por acción y no culpa in omittendo, como quedaría demostrado del pasaje del D. 7, 1, 13, 2, que excluye del ámbito de aplicación de la lex Aquilia las conductas omisivas y ello habría justificado el otorgamiento de otras acciones, repitiendo el argumento de Rotondi ${ }^{16}$.

${ }^{14}$ Arangio-Ruiz, cit., pp. 221-224. El autor se basa en varios pasajes, relativos al mandato y la sociedad, en los que la palabra culpa parece haber estado referida a la producción del resultado dañoso y no un criterio de imputación, agregando que la acepción clásica de la palabra fue revisada falsamente por los bizantinos, para convertirla en un criterio de la responsabilidad.

15 Arangio-Ruiz, cit., pp. 224-225.

${ }^{16}$ Arangio-Ruiz, cit., pp. 226-230. Watson, A., "D. 7. 1. 13. 2 (Ulpian 18 ad Sab.): the lex Aquilia and decretal actions", en IURA 17, 1966, pp. 175 y ss., analizando el pasaje, agrega que en muchas 
Con estas premisas el autor va a argumentar que era precisamente la sanción de la culpa comisiva la que demostraría en el pensamiento clásico una semejante valoración entre culpa contractual y extracontractual. Para él, los romanistas modernos no se han centrado en el concepto de culpa, sino en el problema de sus grados, según la máxima del D. 9, 2, 44pr: In lege Aquilia et levissima culpa venit, así como la distinción entre culpa lata y leve del D. 30, 47, 5, de modo que algunos han considerado que la culpa levissima constituye una exigencia superior al buen padre de familia y otros han propuesto que se refiere a este parangón ${ }^{17}$.

En definitiva, luego del análisis de algunos textos del Digesto relativos a la lex Aquilia, como el caso del podador, que contiene la definición de culpa de Quinto Mucio, en D. 9, 2, 31pr., respecto del que concluye, desde luego, que cualquier referencia a la culpa es fruto de una interpolación justinianea, así como un estudio comparado de las acciones reales, llega a estimar que todo el contexto de la lex Aquilia excluía originariamente la culpa y que por tanto, resultaría difícil pensar que el delito de damnum fuera la excepción. Pone el caso de la reivindicación cuando pendiente la decisión del juicio el poseedor dañaba o deterioraba la cosa. Indica que se trataba de un tipo de responsabilidad muy similar a la de la lex Aquilia. En estos casos, también la culpa fue un agregado posclásico, que permitió completar el esquema de responsabilidad junto con el dolo.

Las conclusiones finales del autor serían como siguen: los clásicos fueron juristas que no desarrollaron instituciones generales ni abstractas, sino que por el contrario, medios técnicos precisos para ir solucionando los problemas que se les fueron planteando. De aquí nacen las principales figuras que delinearán la responsabilidad contractual; en cambio, la jurisprudencia bizantina amaba los conceptos generales, las particiones sistemáticas, las deducciones de la regla de la vida social, sacrificando la satisfacción de intereses por la coherencia del sistema. Así va a emerger la tríada dolus, casus, culpa ${ }^{18}$.

oportunidades las expresiones legis actio Aquiliae, Aquilae actio y lex Aquilia fueron usadas para incluir las acciones decretales, que fueron otorgadas en circunstancias cercanas al ámbito de aplicación de la ley, como en el pasaje del texto, en el que se trataba de una conducta omisiva. Esta conclusión, según el autor, tendría algunas consecuencias: primero, que las acciones decretales que rodearon la lex Aquilia se habían desarrollado para una amplia gama de circunstancias, pudiendo ser consideradas parte integral de la ley ordinaria; segundo, que los textos muestran claramente la gran dependencia de los juristas respecto de las acciones decretales para lograr la plena extensión del damnum iniuria datum; tercero, que los juristas normalmente trataron la ley del punto de vista de las acciones, pero este texto muestra que aun con respeto a las instituciones se podía mantener una opinión más amplia; cuarto, que hay otros textos en los que se utilizó la expresión actio legis de manera general, donde uno esperaría el otorgamiento de una acción decretal, como por ejemplo, en la opinión del Celso en Coll 12. 7. 10 (Ulp. 18 ad ed). Como cita el mismo Arangio-Ruiz, Ferrini, C., Diritto Penale Romano, L' Erma di Bretschneider, Roma, 1976, p. 251, estima que hay varios casos en los que se hacía responsable por haber omitido determinadas precauciones. Se trataba siempre de precauciones destinadas a evitar que un acto u obra propia causara daño; de modo que no se sancionaba la omisión misma, sino la actividad que podía resultar dañosa y pone como ejemplo D. 9, 2, 28 pr-1.

${ }^{17}$ Arangio-Ruiz, cit., p. 233, siendo muy ilustrativo el esquema que sobre estas discusiones desarrolla el autor.

${ }^{18}$ Arangio-Ruiz, cit., pp. 34-54. Aunque solo refiriéndose al problema custodia y culpa, vale la pena indicar que Vazny, G., "Svolgimento della responsabilità per colpa nel diritto romano", en AA.VV. Acta Congressus Iuridici Internationalis, Intituti Utriusque Iuris, Roma, 1935, pp. 347-349, presenta una posición 


\section{B. La culpa como negligencia}

La tesis opuesta a la que venimos comentando, tal como ocurre en materia de la custodia, sostiene que tanto en el período clásico como en el derecho tardío la culpa fue entendida como desviación de un estándar de responsabilidad; en otras palabras, la culpa como falla en el cuidado que un buen padre de familia debió haber ejercitado, excepto en aquellos ámbitos en que culpa se entendió como culpabilidad, incluyendo el dolo.

Uno de los principales defensores de esta corriente es Voci. Este autor centra una parte de su estudio en la diligentia, que es a la que vamos a referirnos brevemente. Para él, el Derecho romano sigue el criterio subjetivo del dolo y la culpa, estableciendo casos de responsabilidad objetiva en supuestos escasos.

En las fuentes literarias romanas la diligentia aparece claramente con un valor ético, como una virtud y se traducía en el ejercicio de una virtud civil. De ahí que resulta fácil conectarla con el bonus pater familias en la vida privada y entonces se hablaba de diligens pater familias. Voci nos muestra la diligencia como un instituto de la moral tradicional romana, de carácter aristocrática. Ahora bien, en el ámbito jurídico, siguiendo siempre a Voci, la diligencia ya se encontraba en las fuentes republicanas, especialmente Quinto Mucio y Servio Sulpicio Rufo. En el campo contractual, puede ser entendida como constitutiva de una obligación para el deudor y una carga para el acreedor. Ahora bien, el incumplimiento de la diligencia, como cualidad positiva de la prestación, acarreaba responsabilidad, que necesariamente debía ser considerada culposa. El sujeto del comportamiento diligente era el bonus pater familias, que describía un modelo de conducta. La desviación de dicho modelo constituía la culpa ${ }^{19}$.

La culpa, según el autor, era entendida en dos sentidos diversos en las fuentes: como el acto o comportamiento que el Derecho consideraba reprobable, en cuyo caso se utilizaban las expresiones culpam admittere u otras análogas, o bien como causa del daño (in culpam esse). El comportamiento culpable podía ser determinado por la voluntad de producir el daño (dolo) o bien debido solo a negligencia o culpa en sentido estricto.

más extrema, al considerar que los juristas clásicos no introdujeron la culpa en el ámbito contractual y que cuando se empleó el término por los clásicos en determinados ámbitos, se le utilizó con sentido amplio, como sinónimo de culpabilidad. Este tipo de argumentaciones, que diferencian categóricamente la forma de trabajo de los juristas clásicos -casuística- y los justinianeos, con una tendencia a la generalización y a las definiciones, es expresamente criticado por MacCormack, "Culpa...", cit., pp. 127-128, quien señala que la circunstancia que los juristas clásicos tuviesen una aproximación casuística a los problemas no significaba que no hubiesen aplicado reglas o utilizado generalizaciones en sus argumentaciones sobre la culpa. Cuando decidían si existía culpa o no, frecuentemente debieron aplicar reglas. En cuanto a que los posclásicos amaban las definiciones y generalizaciones, sostiene que ello no permite demostrar que estos aplicaron reglas sobre la culpa desconocidas por los clásicos, sino, al contrario. En suma, que la distinción viene de la mano de la opinión que a menudo encuentra interpolaciones en los textos clásicos, pero que tales distinciones no tienen fuerza en sí mismas y que se refuerzan con argumentos lingüísticos, pero no dan suficientes garantías de la diferenciación.

${ }^{19}$ Voci, "Diligentia, Custodia, Culpa...", cit., pp. 33-37. En la materia contractual señala que la diligencia se presentaba de dos maneras: en la custodia de la cosa, que suponía prevenir actos dañosos que no provenían del deudor y la diligencia en la administración de bienes. 
Agrega que el significado usual de culpa era el de comportamiento negligente. Estos análisis son desde luego aplicables al ámbito aquiliano, pues era precisamente en dicha materia en la que habría surgido el empleo de la culpa. La culpa como instituto tuvo partida de nacimiento con Quinto Mucio y la famosa definición del pasaje del D. 9, 2, $31 \mathrm{pr}$, la que habría sido interpretada desde los clásicos a partir de la diligencia ${ }^{20}$.

Otro autor que merece destacarse en este grupo doctrinario es Visky, quien luego de analizar varios textos del Digesto relativos a la lex Aquilia, estima que resulta incontestable que esta ya se había presentado claramente entre los jurisconsultos republicanos, con dos significados. En uno muy amplio, comprendiendo el dolo y el otro estricto, como negligencia. De esta forma, los veteres habían tenido oportunidad de analizar bastante a fondo el problema de la negligencia, utilizando como principales ejemplos los pasajes de Quinto Mucio en D. 9, 2, 31 y Alfeno en D. 9, 2, 52. De este modo, la culpa viene a ser un grado intermedio de responsabilidad entre el dolo y el casus $^{21}$.

Por último, merecen destacarse a nuestro juicio, nuevamente, los aportes de Daube. Según este autor, los romanos utilizaron la culpa en dos sentidos: un sentido muy amplio se empleaba para incorporar tanto el dolo como la negligencia. En dicho entendimiento, que según el autor parece haber sido el primero, la culpa equivalía a la falta. En un alcance restringido, incorporado paulatinamente, la culpa fue utilizada como sinónimo de negligencia. Según Daube, este carácter oscilante del concepto siguió siendo importante durante todo el Derecho romano. Así, por ejemplo, en el pasaje de Paulo, en las Instituta de Justiniano, 4, 4pr, tratándose de los daños a la propiedad, se trataba la culpa como condición de responsabilidad, cubriendo la expresión tanto el dolo como la negligencia. Como los otros autores que defienden esta tesis, piensa que en el ámbito aquiliano la utilización de la culpa en sentido estricto, es decir, como negligencia, habría comenzado en el pasaje de Quinto Mucio Scaevola, en D. 9, 2, 31 pr y posteriormente, 6 años más tarde, con la decisión de Alfeno Varo, en D. 9, 2, 52, 4. Fuera del terreno aquiliano, entre las decisiones de Mucio y Alfeno Varo, cita la decisión del Servio, en D. 24, 3, 66pr, quien declara que el marido es responsable por dolo o culpa por los bienes recibidos en la dote ${ }^{22}$.

\footnotetext{
${ }^{20}$ Voci, "Diligentia, Custodia, Culpa...", cit., pp. 40-44. Véase también Voci, P., Istitutizioni di Diritto Romano, Giuffrè, Milano, 1954, p. 422.

${ }^{21}$ Visky, cit., pp. 448 y ss. Una crítica a la concepción de la culpa-negligencia como grado intermedio entre dolo y casus puede encontrarse en Martínez Sarrión, A., Las raíces romanas de la responsabilidad por culpa, Bosch, Barcelona, 1993, p. 238, quien entiende que dolo y culpa constituían categorías jurídicas que solo se asemejaban en el resultado lesivo.

De otra parte, podemos considerar el planteamiento de Visky como una de las tesis más extremas, desde el punto de vista de la temporalidad, pues a diferencia de otros, considera que la culpa estaba configurada desde la época republicana. La aparición de la culpa como fruto de los juristas tardorrepublicanos ha sido sostenida también por Burdese, cit., p. 531.

${ }^{22}$ Daube, D., Roman law. Linguistic, social and philosophical aspects, Edinburg University Press, Edinburg, 1969, pp. 145; 153-155. Podría pensarse que Daube arranca de presupuestos similares a los de Rotondi, "Dalla lex...", cit., vol. XIV, pp. 953-957, para conceptualizar la culpa como negligencia, en el sentido que según el autor la lex originariamente exigía una conducta corpore corpori, lo cual implicaba que en la lex Aquilia se sancionaron solo conductas comisivas, mientras que la consagración de la culpa suponía arribar
} 


\section{La culpa como falta}

Esta tesis ha sido desarrollada por varios autores de manera independiente, que a nuestro juicio buscaron diferentes aproximaciones para resolver los problemas que planteaba y sigue planteando la responsabilidad en el Derecho romano. Según esta teoría la culpa, tanto en el período clásico como posteriormente, expresaba la conducta que podía ser considerada como una materia de reproche individual. Autores con posiciones tan dispares como Cannata, Schipani, MacCormack se circunscriben dentro de esta tesis. Nos referiremos a algunas de estas aproximaciones ${ }^{23}$.

\section{La contribución de MacCormack}

A nuestro juicio, una lectura global de los trabajos del jurista inglés debe llevarnos a resumir su pensamiento de la siguiente manera: MacCormack arranca desde un juico

a una responsabilidad por omisión. No es esta la aproximación de Daube. Si se analiza su trabajo, Daube, D., "On the use of the term damnum", en AA.VV. Studi in onore di Siro Solazzi, Casa Editriche Eugenio Jovene, Napoli, 1948, pp. 98 y ss., refuta que el texto originario de la ley haya exigido que el daño se causara corpore corpori. En efecto, Daube hace un estudio detallado del término damnum en las fuentes romanas, tanto en la literatura como en las leyes, para concluir que este significaba la pérdida o gastos en los que incurría el propietario. Un análisis le permite concluir que el damnum, técnicamente considerado, no se refería al perjuicio inferido sobre el objeto, sino más bien a las pérdidas infligidas al propietario. En suma, el término damnum jamás fue ocupado para referirse ni a las acciones materiales de la ley ni al deterioro o destrucción de las cosas. Aquí se encuentra el punto en cuestión, pues debido a que el capítulo primero solo contenía una hipótesis concreta, estableciendo una sanción fija, el término damnum solo fue ocupado en el capítulo tercero -para referirse al primero, los autores solo habían ocupado la expresión occidere-. De modo que dicho capítulo contenía el principio del id quod interest, pues había permitido la valoración de los menoscabos, pérdidas y gastos efectivamente sufridos por el propietario, con independencia de la afectación material del bien -animado- de su propiedad. Una de las consecuencias de este punto de vista es precisamente que la ley no consag ró ningún principio damnum corpore corpori. Sostiene que tanto Gayo como Justiniano, después de él, declararon que la lex era disponible solo si quis corpore suo damnum dederit, que es bien distinto a sostener que en la lex se exigía un damnum dare corpori. De esta manera: ...damnum corpori datum and, of course, damnum corpore corpori datum cannot be reconciled with the Roman usage. La expresión habría sido el resultado de una introducción de los juristas medievales, desde que el daño no era utilizado para la destrucción o deterioro de las cosas, sino que para las pérdidas sufridas por el propietario.

${ }^{23}$ Por cierto, no puede pretenderse que esta perspectiva haya sido patrocinada solo por estos autores, sin perjuicio que su trabajo se nos presenta como los más acabados. En esta línea se mueve, por ejemplo, Talamanca, Istituzioni, cit., p. 627, quien rechaza la consideración de que la responsabilidad en la lex Aquilia estuviese limitada a la mera causalidad. Por el contrario, la considerable casuística, advierte, indica que el delito de damnum se presenta como un régimen fundado en el dolo o la culpa. Véase también, en un sentido similar a Volterra, cit., p. 561. Según el autor: El elemento del dolus y de la culpa propiamente dicha, esto es, a distinguir el caso que un sujeto efectúa voluntariamente un acto dañoso, sin tener derecho a ello, conociendo y previendo las consecuencias lesivas del mismo, del caso en que el acto dañoso es debido a la inobservancia por parte del sujeto de normas habituales de prudencia y conducta. El elemento del dolus o de la culpa en la realización del acto dañoso, por tanto, pasa a ser un requisito necesario para la existencia del damnum iniuria datum a partir del siglo II, como se hace evidente por el texto de las Instituciones de Gayo. Surge así y se desarrolla en los textos de los juristas, a propósito de la lex Aquilia, el concepto de la culpa extracontractual o aquiliana. Nos parece a nosotros que, en Chile, el profesor Guzmán Brito promueve un concepto más amplio que el de la negligencia. Véase Guzmán Brito, A., Derecho Privado Romano, LegalPublishing-Thompson Reuters, $2^{a}$ edición, Santiago, 2013, t. II, pp. $290-291$. 
crítico de la utilización de las nomenclaturas del derecho moderno para referirse a los problemas del Derecho romano. Así, hemos visto cómo descarta la utilización de la dicotomía responsabilidad objetiva-subjetiva empleadas en relación con diversos aspectos de la responsabilidad en Derecho romano y al menos en el ámbito de la custodia, no es de la opinión que se trate de un criterio de responsabilidad.

También según el autor, los problemas de responsabilidad en Derecho romano pueden abordarse desde dos ángulos distintos: como contenido de la obligación y como criterio de responsabilidad. Además, utiliza las categorías anglosajonas de criterio, estándar y principio para referirse a las cuestiones de responsabilidad en Derecho romano ${ }^{24}$.

Desde el punto de vista del desarrollo histórico, según MacCormack, las sociedades primitivas y orales, en las que no se había alcanzado la escrituración, pensaban en términos más bien objetivos que subjetivos, no porque desconocieran la distinción entre acto intencional y accidental, sino porque había dificultades de prueba. Si bien es cierto diferenciaron entre actos intencionales, descuidos y accidentes, no tenían capacidad para formular reglas generales. Cuando alcanzaron la escrituración y promulgaron sus primeras leyes, todavía existía un pensamiento concreto y todo lo que podían hacer era seleccionar un conjunto de situaciones que típicamente hacían surgir un conflicto.

Agrega que este es el estado en el que más o menos se encontraba el desarrollo del Derecho romano en sus etapas arcaicas, especialmente en el tiempo de la dictación de las XII Tablas y las legis regiae. En cuanto a las XII Tablas, estas describían simplemente ofensas que no hacían referencia a la intención, salvo el asesinato y el incendio. Tratándose de las injurias físicas (membrum ruptum, os fractum e iniuria) el autor adopta una posición escéptica, pues indica que no puede afirmarse, sin arbitrariedad, que dichos delitos requirieron de un elemento intencional o de la falta de este para configurarse ${ }^{25}$.

MacCormack se pregunta si durante el período clásico se atendió a la presencia de la reprochabilidad como un estado mental dado como un ingrediente de la ofensa o bien a la reprochabilidad como un criterio de responsabilidad. En el primer caso, el delito mismo no se entiende si no existe un estado mental. En el segundo, por el contrario, no se atiende a la esencia del delito, sino a la presencia de las condiciones que deben ser satisfechas antes que ocurra el hecho merecedor de responsabilidad. Ahora bien, tratándose de la lex Aquilia, el autor plantea el problema en términos indirectos. En efecto, señala que la cuestión está en determinar si la palabra iniuria occidere, en el capítulo primero, constituía una condición esencial para su comisión o si, por el contrario, el delito consistía esencialmente en un acto de muerte, incurriendo en responsabilidad solo si había iniuria. Aunque ambas perspectivas le parecen sustentables, se inclina por la primera, es decir, que la iniuria podría haber hecho referencia a la ofensa misma, pero en la medida que fue interpretada como ilicitud, adoptó un grado de vaguedad. En otras palabras y tal como lo entendemos, como consecuencia de su línea de pensamiento

${ }^{24}$ MacCormack, G., “'Dolus', 'Culpa' and 'Diligentia'. Criteria of Liability or Content of Obligations”, en Index 22, 1994, pp. 189-190 y MacCormack, G., "Juristic use of the term Dolus: Contract”, en ZSS 100,1983 , pp. 520 y ss.

${ }^{25}$ MacCormack, “'Dolus', 'Culpa' and 'Diligentia'...”, cit., pp. 191-193. 
en todos los órdenes de responsabilidad, el autor estima que los juristas romanos no desarrollaron, a propósito de la lex Aquilia, propiamente criterios de responsabilidad, lo que le lleva a sugerir, como veremos, que los juristas romanos no adoptaron la culpa como negligencia, es decir, refiriendo la desviación del comportamiento a un modelo del buen padre de familia ${ }^{26}$.

En el derecho justinianeo, el autor se pregunta si las Instituciones de Justiniano, comparadas con las Institutas de Gayo, permiten concluir que los trabajos de los juristas tardíos se tradujeron en el desarrollo de criterios, estándares y principios. Aun cuando reconoce que dicho texto evidencia una mayor sistematización y generalización en el uso de los conceptos dolo y culpa en relación con las Institutas de Gayo, ello no se tradujo tampoco, tal como ocurrió en el período clásico, en la construcción de criterios de responsabilidad; además sostiene que uno no puede asumir que dicho trabajo de generalización se debe exclusivamente a los compiladores, pues se ocuparon de textos clásicos que podrían haber empleado tipos generales. En lo que toca a la lex Aquilia, sostiene que Justiniano presta más atención que Gayo al dolo y a la culpa, pero no hay nada en sus Instituciones que indiquen que el dolo o la culpa fueron tratados como criterios, estándares o principios de responsabilidad ${ }^{27}$.

Ahora bien, la solución para el juicio crítico de las posiciones que debaten la cuestión desde las posiciones subjetivas versus objetivas y la conceptualización de la culpa y el dolo como criterios de responsabilidad es encontrada por el autor en un concepto más amplio y funcional de la culpa. De este modo, ya no construye su sistema sobre la custodia o la culpa como mero nexo de causalidad o con sentido estrictamente objetivo, de una parte, o bien como estricta negligencia, de otra, sino que va a considerar la culpa como falta.

Si bien resulta relativamente sencillo distinguir esta tesis de la objetiva, por el contrario, es más difícil comprender cuál es la diferencia entre la tesis de la culpanegligencia versus culpa-falta. Desde la perspectiva de MacCormack, hemos visto que dicha diferencia se explica porque el autor elabora una compleja argumentación y una profunda investigación, en gran parte de sus trabajos, destinadas a descartar que en Derecho romano se hubiere utilizado la culpa como criterio de responsabilidad. De ahí que la custodia se le conciba como contenido de la obligación y la iniuria desde la perspectiva de la esencia del ilícito aquiliano. Por lo mismo, la culpa vinculada a ambos, como consecuencia del hecho dañoso, constituye un concepto más amplio que la negligencia, entendida como desviación de un patrón abstracto.

MacCormack le da mucha importancia a esta distinción. En efecto, como el mismo autor indica, cuando los juristas modernos definen la culpa en el Derecho romano como negligencia, consideran que los juristas romanos habrían utilizado esta en la misma forma en la que es entendida por los juristas ingleses modernos, es decir, implica preguntarse si con la conducta desplegada, el demandado estuvo en posición de prever el daño causado o más bien si debió haber previsto que la acción u omisión le

\footnotetext{
${ }^{26}$ MacCormack, “Dolus, Culpa and Diligentia...", cit., pp. 194-195.

27 MacCormack, “Dolus, Culpa and Diligentia...”, cit., pp. 199-202.
} 
causaría daño a un tercero. Ahora bien, la negligencia implica tomar la falta de cuidado con arreglo al modelo del buen padre de familia. En cambio, la culpa como falta es tomada en un sentido mucho más amplio que la negligencia, para referirse en general a un comportamiento reprochable, pero sin referencia a un modelo, dejando abierta la naturaleza del comportamiento ${ }^{28,29}$.

Hechas estas consideraciones previas, pasemos ahora al estudio del corazón de la tesis de MacCormack. ¿Qué quiere decir exactamente el autor cuando se refiere a la culpa como falta? Indica que tiene dos sentidos: de un parte, puede significar quebrantar una regla de Derecho, pero no el quebrantamiento de cualquier regla, sino solo aquellas que

${ }^{28}$ Las conceptualizaciones de ambas tesis y sus diferencias se obtienen de un estudio combinado de MacCormack, “Aquilian culpa...”, cit., p. 202 y MacCormack, "Culpa...”, cit., pp. 124; 126-127; 133134. En el primero se refiere al tratamiento de los textos, el segundo tiene un carácter más dogmático. Un comentario muy interesante que hace este autor dice relación con una discusión cercana a la dicotomía que venimos comentando. Así, indica que en doctrina la culpa puede entenderse desde dos puntos de vista: subjetivo y objetivo. En la culpa subjetiva se toma en cuenta el estado mental del sujeto, su capacidad para reconocer las consecuencias de su conducta. En cambio, la culpa objetiva puede ser entendida a su vez, desde dos diversos puntos de vista: o bien se entiende que la hay cuando se toman en cuenta las circunstancias externas y de acuerdo con ellas se evalúa la existencia de la falta; o bien suponiendo que los juristas hacen una evaluación de las habilidades mentales y físicas de un hombre promedio, se determina si el sujeto se comportó de acuerdo con la forma que se esperaba, de modo que si su conducta no cumple dichas expectativas y resulta un daño, la culpa podría ser atribuida. Desde luego el autor, y esto es lo más importante, entiende que la culpa en el Derecho romano suponía que los juristas consideraron el estado y las habilidades mentales del sujeto.

Además, dedica algunas páginas a examinar las relaciones de la culpa con otros elementos. Desde luego, por ahora nos interesa las vinculaciones de la culpa con la negligencia. Para MacCormack esta relación operaba en una variedad de combinaciones. Así uno encuentra textos en que el sujeto era responsable por culpa y/o por negligencia, como por ejemplo en D. 8, 3, 35. Obviamente, en este contexto culpa no se utilizó como sinónimo de negligencia, sino que significaba falta en general, siendo agregada la primera porque la falta primordialmente relevante era el descuido. En otras oportunidades, culpa se utilizaba como sinónimo de negligencia, como en D. 17, 2, 72. Para el autor, tales definiciones no implicaban que culpa debiera ser tomada siempre como negligencia, pues aunque se trataba de una aplicación errónea, el significado estaba forzado por la importancia en la ley de una particular falta que se había producido. Lo mismo se aplicaría a los casos en los que se utilizaba la expresión negligencia, cuando uno debería esperar el empleo de culpa, como en D. 48, 3, 12 y en aquellos textos en que los términos se utilizan intercambiados (cita D. 26, 7, 9). Finalmente, en otros textos los juristas se contentaban con determinar la existencia de negligencia, sin indagar si en dicho caso se había producido culpa. En suma, los escritos no probarían que culpa se entendió como negligencia; ocasionalmente, en un contexto particular, culpa era usada en el sentido de falta constituida por negligencia. Esta fue considerada como una falta de la suficiente importancia para garantizar un nombre separado y un tratamiento diferenciado. Finalmente, la equiparación errónea entre culpa y negligencia sería la que habría conducido a reducir el papel de esta y a considerar gran número de textos interpolados.

${ }^{29}$ Una plena coincidencia con el planteamiento general de MacCormack puede leerse en Zimmermann, cit., pp. 1008-1009, quien entiende que los romanos se aproximaron a los problemas de la culpa -como a los de la causalidad- de una manera casuística, de forma tal que no subsumieron el tratamiento de los casos a un estándar. La previsibilidad y el descuido fueron materias importantes, pero ellas no determinaron conclusivamente los problemas de responsabilidad. El punto principal fue la cuestión de la falta, es decir, si el demandado se comportó como debió haberse comportado, lo que dependía de la evaluación de todas las circunstancias del caso, de manera que solo en algunos aspectos puede advertirse cierto grado de generalización, como por ejemplo la imperitia culpae. 
prescriben formas de comportamiento. En un segundo sentido, no implica más que el comportamiento prohibido que quebranta la regla y que como consecuencia acarrea responsabilidad. En este sentido, según los casos, culpa podía representar una ofensa en general o en un comportamiento prohibido por un rango de reglas, bien una ofensa en particular.

Así, la culpa se presenta con un sentido muy amplio y funcional, pudiendo variar dependiendo del tipo de relación, pero todas ellas tienen la nota común que se refieren a una conducta que puede ser objeto de reproche individual. Particularmente tratándose de la lex Aquilia, MacCormack piensa que una persona no era declarada responsable como consecuencia de una particular posición en sus relaciones jurídicas, ni como consecuencia de una falta en la observación de los intereses de otro, sino que era reprochable la conducta en la que había faltado el ejercicio adecuado de sus facultades mentales, fallando en la apreciación de sus consecuencias ${ }^{30}$.

Finalmente, profundizando sus opiniones en relación con la lex Aquilia (pues su trabajo comprende un profuso análisis de la culpa en variados ámbitos, desde el derecho criminal hasta todo tipo de relaciones contractuales), sostiene que unas veces la responsabilidad se fundó en el descuido, como en el caso del podador (D. 9, 2, 31pr.), en otras en la impericia, como en D. 9, 2, 8pr; en otros grupos de casos, cuando existían colisiones de bienes y resultaba un daño, la culpa era declarada cuando un sujeto había tenido el poder de tomar las medidas para evitar el daño y no lo había hecho, como en D. 9, 2, 29, 2; finalmente, cuando se desarrollaba una actividad en un lugar peligroso, del que podía derivar daño a un tercero, como el caso del barbero (D. 9, 2, 11 pr). Reitera que los juristas utilizaron la culpa en diversos contextos, de modo que la expresión entendida en uno de ellos podía diferir de la utilizada en $\operatorname{otros}^{31}$.

\footnotetext{
${ }^{30}$ MacCormarck, "Culpa...", cit., pp. 142-144; 174-176. Son los distintos tipos de relaciones jurídicas los que permiten comprender el diverso contenido de la culpa en el ámbito contractual, de modo que el desarrollo de la culpa fue diverso en un tipo de relación u otro. Muestra varios ejemplos en los que varían tanto las obligaciones como la configuración de la culpa en diferentes contratos. Advierte que lo difícil en todos estos casos es determinar los principios que guiaron a los juristas en cada una de estas relaciones, pero en general puede decirse que algunas se explican solo si se asume que determinaron la responsabilidad de acuerdo a si una persona conoció o debió conocer que otro había adquirido intereses mediante un particular vínculo legal y dichos intereses fueron, aun así, menoscabados. Ahora bien, tales delineamientos no son trasladables al desarrollo de la culpa en la lex Aquilia, pues la declaración de responsabilidad no dependía de la evaluación acerca de si una persona había infringido los intereses de otro, protegidos por la relación jurídica en la que se encontraba, sino que los juristas hacían una evaluación de la capacidad mental del dañante, es decir, averiguaban si este tenía habilidad suficiente para determinar las consecuencias de sus actos. Opiniones idénticas a propósito de la lex Aquilia, a modo de conclusión en MacCormack, "Aquilian culpa...", cit., p. 219.

${ }^{31}$ MacCormack, “Culpa...”, cit., pp. 172-173. En MacCormack, “Aquilian culpa...”, cit., pp. 205 y ss., el autor desarrolla o agrupa los casos decididos por los juristas en varios tipos: decisiones por el escape de fuego, por colisiones, por impericia, por actos hechos en su tierra y como consecuencia resultaba un accidente derivados de juegos o bromas y, por último, unos pocos grupos de situaciones que no pueden ser encuadradas en las categorías anteriores, para mostrar que los juristas romanos alcanzaron cierto grado de generalización en las reglas sobre la culpa.
} 


\section{La tesis de Schipani}

En esta línea, aunque con una metodología completamente diversa y con finalidades también diferentes, claramente podemos encuadrar en este sector doctrinario a Schipani. Este autor identifica dos visiones sobre la culpa. La primera posición pone en evidencia que la culpa se encuentra objetivada, en el entendido que se articula como una transgresión de una norma, sea moral o jurídica. Dos críticas propone Schipani para esta posición. La primera, que desde este punto de vista no se indica exactamente el contenido de la norma violada, es decir, si se trata de un deber o de una obligación. En segundo lugar, el autor enfatiza que debe destacarse que la culpa fue entendida indicando un hecho separado de su autor, lo que pone en evidencia la gramática latina, es decir, que el término fue empleado solo en singular, pero agrega que el uso del término en plural se encuentra a partir de Cicerón y muestra su utilización por Plauto y Terencio, de quienes derivan expresiones como commerere culpam in se, admittere culpa in se, de los cuales se puede considerar derivado commere culpam, admittere culpam, principalmente ligados al significado objetivo de hecho cometido, en los que es naturalmente accesible el plural.

El singular era más abstracto y se refería al sujeto. Aquí se relaciona la otra posición, según la que culpa significaba Schuld (culpabilidad, deuda) o Verschuldung (endeudamiento), que pone el acento en la posición del autor frente al hecho; así se distinguiría entre el reconocimiento en el sujeto de la causa del hecho y el reconocimiento de la cualidad del autor, poniendo énfasis sobre las características del comportamiento consciente y voluntario de la intervención de este en la serie causal que podía verificarse entre el hecho y la ilicitud del primero. La primera idea pertenece a Pernice y la segunda a Voigt, entre otros. Señala Schipani que de este enfoque no resulta exactamente aclarada la relación entre comportamiento subjetivo e infracción de una norma; en particular, esta corriente, que critica, no profundiza en las características de la conducta, limitando el juicio desfavorable al hecho y no al carácter referido a la voluntad del sujeto agente. Esta evaluación conduce al autor a optar por el punto de vista contenido en el Thesaurus Linguae Latinae, que define culpa como malum, lo que se traduce en un comportamiento que, en sí y por sí mismo, es objeto de un juicio desfavorable. Este es la perspectiva que le parece correcta al autor, como intenta $\operatorname{probar}^{32}$.

Ahora bien, según el análisis de Schipani, la palabra tuvo una extrema variedad en los autores latinos, que puede considerarse desde diversos puntos de vista. En primer término, se trataba siempre de hechos valorados como un mal, es decir, que cuando se hacía referencia a la culpa por los autores latinos, estaba insertada en un contexto en que delineaba una situación desfavorable, en cuanto se trataba de un daño, error, violación de un derecho o de la moral. Cuando la conducta era valorada positivamente, no se hablaba de culpa. Así, explica que se empleara de la palabra en múltiples contextos delictuales (homicidio, daño, lesiones); respecto de varios sujetos (personas e incluso animales);

${ }^{32}$ Schipani, S., Responsabilità "Ex lege Aquilia". Criteri di imputazione e problema della "culpa", Giappichelli, Torino, 1969, pp. 93-97. Sobre la identificación de la culpa con malum, como el mismo Schipani advierte, puede consultarse el Thesaurus Linguae Latinae, Lipsiae, Leipzig, 1906-1909, vol. 4º pp. 1296 y ss. 
el ámbito normativo (moral o jurídico). En relación con el elemento específico de la situación que viene caracterizada con el término culpa, se refiere al hecho íntegro, a la sola conducta, a la sola lesión, etcétera.

Agrega que en esta variedad se puede localizar siempre la misma característica de la situación considerada, inherente a la conducta del sujeto agente, cuya presencia es siempre necesaria y suficiente para fundar el reconocimiento de la presencia de culpa. Es decir, que el autor reconoce una característica común para el amplio grupo de casos. La única diferencia relevante que encuentra es la utilización de la culpa para referirse tanto a la actuación de personas como a la participación de animales o cosas en un resultado determinado ${ }^{33}$.

Profundizando en su estudio, se refiere a hechos apreciados desfavorablemente, desarrollados en relación con la acción o la eficiencia causal de una cosa o animal. La culpa vinculada con las cosas se utilizaba en términos causales. De paso, digamos nosotros que no es difícil comprender este uso, pues hoy puede hablarse en términos ordinarios que ciertos fenómenos, cosas o animales han tenido culpa, como equivalente a la causalidad. Por ejemplo, entre otros, cita un caso en el Plauto, quien atribuye la culpa al vino por determinado hecho. Seguidamente se refiere a hechos estimados desfavorablemente, desarrollados en relación con la conducta de una persona. Aborda las características de esta construcción. Primero, que la conducta del sujeto agente es de por sí objeto, un juicio desfavorable de reproche, explicando en qué contextos, es decir, cuándo la expresión estaba ligada a determinados verbos, sustantivos o adverbios. Luego de analizar algunos textos señala que no puede entenderse que la culpa pudiera fundarse sobre la mera existencia de un relación entre la conducta del sujeto y el resultado negativo; la característica no era solo la no conformidad con el bien hacer, sino la contrariedad de ese bien hacer en línea más general, es decir, su potencial dañosidad.

La segunda característica consiste en que el agente pudo desarrollar una conducta distinta, agregando que tal característica surgía de una serie de casos completamente diferentes, pero en todos ellos aparecía implícita la posibilidad de tener una conducta alternativa. Divide este número en dos grupos: aquellos en los que se tomaron en cuenta factores externos y los que se consideraron los factores internos del agente. Este último aspecto constituye en opinión del autor uno de los puntos más delicados del problema. En este ámbito cita ejemplos de imprudencia, inscientia, que fueron motivo de exclusión de la culpa. También el lapsus y el error constituyeron excluyentes de ella ${ }^{34}$.

Hay un apartado muy interesante, en el que hace una precisión entre culpa y relación de causalidad. La culpa importaba un plus a la relación de causalidad, pues se refería a un juicio de reprochabilidad de una conducta considerada desfavorable. Finalmente, antes de la exégesis de los textos, en los que va a ir determinando los sucesivos aportes desde los republicanos hasta los clásicos, hace una consideración sintética de los pasajes republicanos. Dichos escritos coincidirían con el empleo del término en el ámbito

\footnotetext{
33 Schipani, Responsabilità "Ex lege Aquilia”...., cit., pp. 98-102.

${ }^{34}$ Schipani, Responsabilità "Ex lege Aquilia”..., cit., pp. 109-124.
} 
literario. Especialmente clara es la regla jurídica que según el Schipani sentaron los veteres a propósito de D. 45, 1, 91, 3, donde culpa designaba la conducta del sujeto que, fuera de las hipótesis de fuerza mayor o caso fortuito, no había observado la obligación a la que se sujetaba, fundándose su comportamiento reprobable en la consecuencia negativa.

En suma, indica Schipani que tanto para los textos literarios como para los jurídicos la culpa significaba siempre un hecho valorado desfavorablemente, un delictum, un peccatum, más genéricamente un malum, del cual el sujeto debía ser reconocido como autor, siendo esencial que el sujeto hubiere estado en condiciones de comportarse de otra manera y en la valoración de los eventuales impedimentos se consideraron factores externos e internos, los últimos inherentes a la voluntad y a la consciencia, pero no se requería la individualización de un comportamiento consciente y voluntario, bastando la no conformidad a un modelo de comportamiento ${ }^{35}$.

Aun cuando no configuraba un delictum, peccatum o malum, la conducta podía ser sujeta a una consideración desfavorable y a una reprochabilidad. La culpa no era la violación de una norma cualquiera, sino la violación de una norma que podía, desde un punto de vista material y consciente, ser evitada. De este modo, la culpa no pudo ser reconducida a la noción de causa y ni siquiera a la mera relación de autor entre el sujeto y el evento ilícito. Como la esencia de la culpa fue un comportamiento desfavorable, estaba conectada con un reproche subjetivo, no comprendiendo solo el comportamiento intencional, sino la falta de control, con relación a un modelo, de los propios comportamientos ${ }^{36}$.

Como resulta imposible sintetizar el trabajo del autor en breves páginas, nos parece suficiente señalar que reafirma las opiniones que hemos expresado precedentemente. Así, analiza in extenso los pasajes D. 9, 2, 39pr y D. 9, 2, 31 pr atribuidos a Quinto Mucio; el pasaje D. 43, 24, 7, 4, de Servio; de Ofilio, en D. 9, 2, 9, 3; de Alfeno, en D. 9, 2, 52, 1-4 y D. 9, 2, 29, 4. Del examen de los escritos republicanos extrae algunas conclusiones interesantes. Señala que aun cuando los juristas resolvieron con extrema adhesión a las situaciones particulares, hablaron de culpa con algunas características de la conducta, pero sin valor descriptivo, conectándose con la individualización de la solución que venía dada. Así, la culpa se conectaba con otros términos, como consulto, data opera, percutere, ex plagis, sua exponte, negligentia, agitare, ducere, etc. Unas veces tenía un interés meramente descriptivo de una conducta, en otras una valoración, un reproche, una conducta intencionalmente destinada a producir el perjuicio; a veces la referencia era más estricta

35 Véase en este sentido, Schipani, S., "Interpretazione della lex Aquilia nei giuristi replicani e il problema della culpa", en Él mismo, Contributi romanistici al sistema della responsabilità extraconttratuale, Giappichelli, Torino, p. 71. Dice Schipani: Nella lingua latina, fino alla fine della reppublica, epoca della sua utilizazione tecnica da parte dei giuristi, il termine culpa era connesso alla presentazione di un fatto che costituisce un malum, e di cui una persona debe essere riconosciuta autore. È neccesario inoltre che tale persona possa comportarsi altrimenti, senza esservi impedita da fattori esterni (natura, deus, fatum, casus, necessitas, aliena vic ad potestas), od interni (imorudentia, inscientia, mancata previsione, lapsus, error), sempre che questi ultimi non siano riconducibili alla violazione di un modelo (per inertia, negligentia, fatuitas) di un modello di comportamento, per cui la sua condotta è passibile di una valutazione sfavorable, è essa stessa direttamente riprovebole.

${ }^{36}$ Schipani, Responsabilità "Ex lege Aquilia”..., cit., pp. 125-130. También, Schipani, "Interpretazione...”, cit., p. 71 
y en la negligencia hacía referencia a un modelo de comportamiento y a veces indicaba el mero cumplimiento de la conducta típicamente causal. Concluye señalando que el reconocimiento de la responsabilidad de un sujeto no fue homogéneo. En ocasiones la culpa no parecía justificable, en otras se encontraba implícita en la decisión y solo para ciertos casos podía considerarse cierta.

Para Schipani la culpa no constituyó un requisito autónomo para fundar la responsabilidad, pues en algunos casos no aparecía reclamada, ni explícita ni implícitamente. Sin embargo, en ella podía verse un presupuesto para el reconocimiento de la presencia de uno de los requisitos legales (iniuria occidere, urere, frangere, rumpere). Así, mientras en algunos casos era inmediata la individualización de los requisitos legales, fuera de una atribución o reproche subjetivo, en otros se asignaba valor al comportamiento del agente y a la reprochabilidad, de modo que durante el período clásico la culpa importaba un reproche de la conducta, que otorgaba un motivo válido para la sanción, pero más que un concepto que podía ser considerado abstractamente, la culpa se desenvolvía desde la interpretación concreta de los requisitos legales ${ }^{37,} 38$.

Por el contrario, el papel de la culpa como regla general y autónoma, dentro del sistema de responsabilidad, puede advertirse ya en la época justinianea. En efecto, en uno de sus trabajos, Schipani hace una comparación entre las Institutas de Justiniano

${ }^{37}$ Schipani, Responsabilità "Ex lege Aquilia”. ., cit., pp. 133-192. Véase también, Schipani, S., "Pluralità di prospettive e ruolo della culpa come criterio elaborato dalla scienza del diritto nell'interpretazione della lex Aquilia”, en Studia Iuridica 12, 1985, pp. 251 y ss.; ahora en Schipani, S., Contributi romanistici al sistema della responsabilità extracontrattuale, Giappichelli, Torino, 2009, pp. 48-51.

38 Schipani, Responsabilità "Ex lege Aquilia”..., cit., capítulo IV, pp. 199-229 continúa la exégesis histórica analizando los pasajes atribuidos a Labeón. Lo que interesa destacar de esta parte de la obra son los contrapuntos que el autor encuentra, en relación con la culpa, entre los juristas republicanos y Labeón. En principio, señala que el método de Labeón era más preciso, pues se sirvió de recursos filológicos, con el objeto de dar a la palabra una definición exacta, de modo que se trataba de uno de los juristas que más profundizaron y desarrollaron las materias de los delitos privados (es autor de la definición de hurto y de sutiles distinciones en el delito de iniuria). En el campo de la culpa, mientras los juristas republicanos realizaron una interpretación dinámica, sirviéndose de la culpa para modificar los requisitos legales, en Labeón, por el contrario, se recurre a esta una vez que se han verificado los requisitos legales. En cuanto a Gayo, capítulo V, pp. 233-257, advierte que con este jurista la culpa pasa a ocupar un papel central, pues asume un rol de relevancia no solo desde un punto de vista cuantitativo, sino cualitativo. Con Gayo queda claramente delineada la distinción dolo-culpa y el acento en la responsabilidad de la lex Aquilia, que a diferencia de otros delitos privados no requería el dolo. En efecto, en pasajes como G, 3,202 o D. 9, 2, 8pr el autor estima que hubo una precisión del concepto de culpa y un esfuerzo por conducirla a un rol central. La culminación de dicha elaboración habría sido gracias a G, 3, 211, con el cual el jurista romano intentó desarrollar el elemento dogmático unitario (dolo y culpa) que permitiera la solución de todos los casos.

Finalmente, destaca los aportes de Ulpiano, en el cap. VI, pp. 259-356, aunque ofrece un panorama mucho más amplio que a menudo excede la exégesis de textos que se refieren solo a la culpa. En el método de Ulpiano puede apreciarse un tratamiento sistemático de las materias, un comentario a la palabra de la ley, mediante definiciones y un método encuadrado en la casuística, que implica la solución de cada aspecto concreto. En lo que toca a la culpa, Ulpiano no realizó un examen directo del elemento subjetivo, sino que atribuyó a la iniuria un valor que tenía en cuenta la voluntad. Así, con Ulpiano la iniuria se desarrolla desde la causa de justificación a la determinación del ejercicio de ese acto autorizado, teniendo como extremos la legítima defensa, de un lado y el dolo, de otro. Por lo que toca a Paulo, le dedica el capítulo VII para analizar sus intervenciones en pasajes antes analizados y para situarlo en un punto medio entre las posiciones de los 
con las Instituciones de Gayo y deteniéndose especialmente en algunos casos decididos por juristas clásicos recogidos en el Digesto. En principio, reitera la idea que la culpa no estaba constituida solo por la negligencia, sino que el concepto de la culpa incluía la idea de negligencia en el sentido de conducta voluntaria censurable, que en cuanto tal constituía un adecuado fundamento por la imposición del castigo. Más adelante agrega: Pero si queremos escoger en modo unitario el significado de la culpa, incluyendo todas las facetas vistas, debemos entender que ella se refiere a una conducta voluntaria probibida sea por lo más de normas de prudencia, pericia, diligencia, sea también, más genéricamente, por otras disposiciones, cuya violación muestra la conducta reprochable. También, sobre la comparación de casos, como el de lanzamiento de jabalinas en J, 4, 3, 4 en comparación con D. 9, 2, 9, 4 reitera que en la época justinianea se produce una sistematización de la culpa como elemento central del sistema resarcitorio, exigiéndose como requisito autónomo para afirmar la responsabilidad, con independencia de la actuación sine iure ${ }^{39}$.

\section{NuESTRO PUNTO DE VISTA}

\section{A. La dicotomía responsabilidad objetiva-subjetiva, ¿adecuada para el Derecho romano?}

Como cuestión previa, en el fondo de la discusión o divergencia entre estas tesis está el problema de determinar si durante el desarrollo del Derecho romano se consagró una responsabilidad objetiva o una subjetiva. Es una discusión, digamos de paso, que se ha planteado tanto en responsabilidad contractual, a propósito de la custodia, como tratándose de la aquiliana. Sin embargo y con bastante razón, varios autores han mostrado

jurisconsultos romanos y los bizantinas, pero que a diferencia de las claras aportaciones de Gayo o Ulpiano, señala que es difícil reconstruir el núcleo sistemático de su doctrina.

Por último, los dos últimos capítulos del autor, cap. VIII, pp. 387-437 y IX, pp. 439-473 se refiere a los aportes en los textos de los juristas prejustinianeos o postclásicos y de la compilación justinianea. En cuanto a los primeros, el tratamiento de los clásicos (Gayo, Ulpiano y Paulo), quienes habían madurado diversamente el problema de los criterios de responsabilidad aquiliana, vienen ahora fundidos en un tratamiento que tiende a enriquecer cada aspecto decidido, a profundizar las decisiones de los clásicos, sin falsearlas. La nota dominante de este período fue la tendencia a considerar la culpa presupuesto esencial y criterio único de imputación de la responsabilidad aquiliana. En la compilación justinianea no hubo un trabajo interpolacionístico aislado, sino uno articulado y complejo. En cuanto a los textos del D. 9, 2, la posición de los compiladores emerge en los pasajes 30, 3-32. En ellas la culpa y el dolo son puestos como elementos esenciales y autónomos. La culpa mantendría su carácter de acto reprochable constituida en la mayoría de los casos por la negligencia, cuya consecuencia es el daño, del cual se responde. Esta concepción aparece particularmente en las Instituciones y puede seguirse también en el Digesto, aunque con el trabajo dogmático de unificación en torno a la culpa.

39 Schipani, S., “Análisis de la culpa en Justiniano 4,3”, en Aída Kemelmajer de Carlucci y Jesús Alberto Bueres (directores), Responsabilidad por daños en el Tercer Milenio. Homenaje al profesor Doctor Atilio Aníbal Alterini, Abeledo Perrot, Buenos Aires, 1997, pp. 127 y ss. Véase también Schipani, S., "Dalla lex Aquilia a D. 9: prospesttive sistematiche del Diritto romano e problema della responsabilità extracontrattuale", en AA.VV, Colloqui in ricordo di Michele Giogianni, Napoli, 2007, pp. 999-1021, ahora en Schipani, S., Contributi romanistici al sistema della responsabilità extracontrattuale, Giappichelli, Torino, 2009, pp. 143-145. 
que puede tratarse de una terminología inadecuada para referirse a los problemas de responsabilidad en el Derecho romano ${ }^{40}$.

En esta línea, especialmente analizando el problema de la responsabilidad por custodia versus la responsabilidad por culpa en sede contractual, Robaye ha señalado que aun cuando contestar si la responsabilidad subjetiva versus objetiva es un buen esquema de análisis para los textos clásicos, una distinción como esta no permite dar cuenta del sistema existente en el Derecho romano, pues la culpa no era un criterio "subjetivo", debido a que su apreciación no estaba referida a las circunstancias particulares del dañante o deudor incumplidor, sino a cierto estándar de conducta; la responsabilidad, así entendida, se centraba en el acto y no en la subjetividad del agente, de modo que decir que un sistema en Derecho romano era subjetivo, implica plantear simplemente que la imputación del daño operó, tanto respecto del deudor incumplidor como respecto de quien había causado materialmente el daño, mediante la apreciación de un comportamiento no adecuado y no por la indagación de la psicología del agente, sus motivos o móviles. Por el contrario, el sistema es objetivo cuando solo se permite tomar al juez la realidad del daño, sin referencia a un estándar de conducta ${ }^{41}$.

${ }^{40} \mathrm{Ni}$ siquiera el vocablo responsabilidad, tan difundido en nuestra ciencia hoy, fue utilizado por los juristas romanos. Además, ya Rotondi, cit., vol. XIV, p. 943, mostraba el peligro de atribuir categorías modernas a las instituciones del Derecho romano, señalando que los sistemas de responsabilidad consagrados en las codificaciones difieren del delito del damnum en cuanto este último tenía una esfera de aplicación más modesta y no el carácter de resarcimiento general que puede encontrarse en los códigos modernos. Ello es porque como explica Arangio-Ruiz, cit., p. 229, una observación preliminar y elemental es que el ámbito de la lex Aquilia no corresponde, al menos en el Derecho clásico, al principio consagrado en las codificaciones, cuyos preceptos establecen una obligación uniforme de resarcimiento del daño, derivado del cualquier hecho del hombre que causa daño a otro. La lex Aquilia, por el contrario, sancionaba con una poena privada, valorada al máximo valor de la cosa dentro de un cierto tiempo. Se trataba de un delito específico de daño a las cosas, que exigía el principio corpore corpori, es decir, un acto positivo corpóreo ejercitado sobre la cosa misma. En el mismo sentido, véase también Voci, P., "L'estensione dell'obbligo di risarcire il danno nell diritto romano classico", en AA.VV. Scritti in onore di Contardo Ferrini pubblicati in occasione della sua beatificazione, Sociedad Editriche Vita e pensiero, Milano, 1934, vol. II, pp. 361-363, quien agrega que la falta de norma general es la característica de todo el período clásico.

Particularmente sobre este tema Cannata, C. A., Ricerche sulla responsabilità contrattuale nel Diritto romano, Guiffrè, Milano, 1966, t. I, pp. 17 y ss., señala que los juristas romanos no conocieron estas categorías, de modo que con el examen de los textos romanos se podrían crear dos nuevos conceptos romanos de responsabilidad objetiva y subjetiva, pero tal intento sería inútil, debido al establecimiento de categorías a priori resultaría ser una pura tautología. Sostiene que determinar si la responsabilidad en Derecho romano era objetiva o subjetiva obedece al deseo de tratar el tema de la responsabilidad de manera sistemática, cuando no estamos en presencia de categorías que puedan fundamentarlo adecuadamente.

${ }^{41}$ Robaye, R., "Responsabilité objective ou subjective en droit romain", en TR 18, 1990, pp. 352 y ss. En tal sentido Cannata, Ricerche..., cit., pp. 17 y ss., agrega que resulta bastante claro el carácter relativo y oscilante de los conceptos de responsabilidad objetiva y subjetiva, por cuanto la primera puede ser entendida como mero nexo de causalidad y la segunda como responsabilidad por dolo o culpa, en cuyo caso se reduce el campo de aplicación de las dos expresiones. Pero además se puede estimar que hay responsabilidad subjetiva siempre que concurra la culpa y objetiva cuando se tengan en cuenta elementos diversos del mero nexo causal, con lo que resulta que ambas nociones acogen un contenido heterogéneo, resultando problemático delinear una distinción entre ellos. En sentido similar, Véase, Voci, “Diligentia, Custodia, Culpa...”, cit., pp. 29-33. 
En suma, las confusiones a las que han hecho alusión estos autores, como queda demostrado en párrafos anteriores, se producen por cuanto hay dos aproximaciones a la responsabilidad objetiva-subjetiva que se confunden en las argumentaciones, de modo que si se toma alguna tesis, como la de Marton, por ejemplo, desde un ángulo podemos considerarla subjetiva, pues entiende que la culpa fue desarrollada por los juristas clásicos, pero, de otro lado, objetiva, por cuanto describe esta como un modelo abstracto y objetivo $^{42}$. Y aun si abordamos la cuestión desde la tesis que ve en la culpa el equivalente a la negligencia, como desviación del modelo de conducta, también podremos predicar de él tanto un carácter subjetivo - por tratarse de culpa- y como objetivo -por el patrón del bonus pater- ${ }^{43}$.

\section{B. Las deficiencias de las tesis objetivista y subjetivista}

A nuestro juicio, el problema de la culpa en la lex Aquilia puede ser leído desde varios puntos de vista, que intentaremos abordar brevemente en este apartado. Así, una primera perspectiva sería la metodológica. Los autores defienden sus visiones, a menudo totalmente contradictorias, en relación con el concepto de la culpa o, mejor dicho, sobre lo que los juristas clásicos, posclásicos y bizantinos entendieron por ella. En sucesivas etapas temporales la doctrina romanista ha pasado desde concepciones objetivistas a otras de carácter subjetivo.

En la segunda parte del siglo pasado aparecen autores que comenzaron a sostener posiciones escépticas, criticando especialmente las categorías utilizadas para enfrentarse a los problemas de responsabilidad en el Derecho romano. Tachando de inadecuada la nomenclatura responsabilidad objetiva-subjetiva y efectuando críticas a los métodos empleados, particularmente al denominado método interpolacionístico, intentaron caminos alternativos, básicamente negando el carácter de criterio de responsabilidad de la custodia -en el ámbito contractual-, afirmando por el contrario su significado de contenido de la obligación y explorando por la vía de un concepto más amplio de la culpa, que no la restringiera solo a la negligencia. Nos parece que en esta materia son destacables principalmente las aportaciones de Cannata, MacCormack y Schipani.

Las tesis objetivas de la culpa han calado hondo en la dogmática civil, pero han recibido serias críticas desde el punto de vista del método romanista. Veamos ahora

${ }^{42}$ Marton, G., "Un essai de reconstruction du développement probable du système classique romain de responsabilité civile", en AA.VV. Mélanges Fernand de Visscher, RIDA, Bruselas, 1949, t. II, pp. 177 y ss.

43 MacCormack, "Dolus, Culpa, Custodia and Diligentia...", cit., pp. 202-203. Según el autor, desde este último punto de vista hay tres modelos de opiniones: aquellos que distinguen entre criterios de responsabilidad que ponen la atención en el estado mental del ofensor (subjetivo) y aquellos que no (objetivo). Desde este punto de vista dolo y culpa se asignan a la primera categoría. Una segunda opinión estima que dolo y culpa son "objetivos", en el sentido que la evaluación de la conducta se hace por referencia a un ideal, a una conducta normal y típica y solo excepcionalmente se indaga el estado mental del agente. La tercera opinión estima que los denominados con el tiempo dolo, culpa y custodia pueden ser tomados en un sentido subjetivo u objetivo. Como veremos, tales apreciaciones encuadran, más o menos, con los distintos conceptos de culpa que ha ensayado la doctrina. 
cómo el método de la interpolación de los textos tampoco favorece una solución de esta naturaleza.

Por ejemplo, Robaye considera que hay una exceso de opiniones sobre las interpolaciones, agregando que el problema radica precisamente en el método empleado para decir cuándo un texto ha sido o no interpolado, pues a menudo se argumenta sobre la base de la distracción de los compiladores. A veces se piensa que estos no comprendieron adecuadamente las reglas clásicas o bien que fueron alteradas o, incluso, se estima que hubo derechamente una agregación. Robaye sostiene que el trabajo de los compiladores del Digesto supuso el estudio y recopilación de más de 3.000.000 de líneas y, por lo mismo, solo se limitaron a cumplir el mandato encomendado en la constitución Deo auctore, eliminando las repeticiones inútiles o contradictorias. De este modo, anota, si las compilaciones hubiesen sido de la entidad que los sostenedores de las tesis objetivas plantean, no hubiesen subsistido las contradicciones que se advierten en los clásicos, más preocupados de resolver las cuestiones concretas que les eran sometidas, que a formular reglas generales, como era la tendencia de los justinianeos. Finalmente, sostiene que el problema de la interpolación no puede caer en una pura valoración gramatical, por cuanto las construcciones gramaticales postclásicas no son una prueba inmediata de alteración del pensamiento de los clásicos; antes al contrario, piensa que los justinianeos reescribieron algunos textos, respetando el pensamiento de sus predecesores ${ }^{44}$.

Pero la objeción más seria de este grupo de opiniones tiene una naturaleza más sustantiva y si se nos permite sistémica. En efecto, este grupo doctrinario considera que la culpa solo importaba en época republicana e incluso clásica, la comprobación del vínculo causal. Pero si la culpa equivalía a la relación de causalidad, ¿qué papel jugó la causalidad en el Derecho romano?, o, aun, ¿qué relaciones había entre la causalidad y la culpa desde este punto de vista? Sobre estos problemas, este sector guarda el más absoluto silencio, refugiándose en sus opiniones sobre la interpretación de los verbos ${ }^{45}$.

Las tesis subjetivistas, con todo, también adolecen de problemas, precisamente desde esta perspectiva sustantiva. En efecto, aquellos que sin más adoptan la culpa como sinónimo de negligencia, es decir, como un criterio de responsabilidad. No se trata, como comprobaremos en el devenir histórico y en el dogmático, que la esencia

${ }^{44}$ Robaye, cit., pp. 350-351. También se ha preocupado de la cuestión metodológica MacCormack, "Culpa...", cit., pp. 127 y ss., quien comparte algunos puntos de vista con Robaye, pero rechaza otros. Así, analizando la opinión según la cual los clásicos resolvieron casos concretos, mientras que los compiladores justinianeos amaban los conceptos generales y abstractos, explica que ello no debe conducir a pensar que los clásicos no formularan reglas o generalizaciones sobre la culpa, así como el argumento que los compiladores amaran los conceptos, tampoco prueba que aplicaran reglas o definiciones desconocidas por los clásicos, sino que al contrario. De ahí que siga que las opiniones que consideran la culpa como producto de los bizantinos carezcan de fundamento, pues importa aceptar una considerable cantidad de textos interpolados y que se basan en un supuesto argumental a priori, fundado en argumentos lingüísticos, que como mucho permiten mostrar que los términos no eran los preferidos por los clásicos o que el texto sufrió una abreviación.

${ }^{45}$ Ello, sin perjuicio de que la indagación filosófica permite descartar por completo la consideración de la culpa en clave objetiva. Véase nuestra tesis doctoral, Aedo Barrena, C., Culpa aquiliana: una conjunción de aspectos históricos, filosóficos y dogmáticos, Universidad de Deusto, Bilbao, 2010. 
del concepto romano de la culpa y su significado técnico se mantuviese hasta nuestros días, sino que la expresión no se articuló nunca en torno a una cláusula general de responsabilidad, como veremos, lo que solo ocurrió con el iusnaturalismo racionalista. Por eso a nosotros nos parece que el camino más profundo para resolver la cuestión es el que ha desarrollado especialmente MacCormack, quien comienza preguntándose si verdaderamente los romanos utilizaron el concepto de culpa como criterio de responsabilidad, de modo que se preocupa no solo de criticar la tesis rival, sino de construir un apoyo suficiente para un nuevo planteamiento, pues como su investigación le lleva a concluir que en ninguna época los juristas formularon criterios, lo que propone es un concepto de culpa más amplio, más elástico, que represente las distintas formas en la que fue interpretada. Y este camino es seguido, en parte por Cannata, al menos en la crítica a la utilización de categorías que no tenían que ver con los juristas romanos y en la búsqueda de un concepto que le permita escapar de la dicotomía responsabilidad subjetiva-objetiva.

Cuando se revisan las argumentaciones de Schipani es fácil encontrar las conexiones entre este autor y MacCormack, pues la forma en la que conciben la culpa, especialmente en el ámbito aquiliano es muy similar, al menos en dos extremos. Primero, ambos conciben la culpa como un concepto más amplio que la negligencia, entendida como desviación de un modelo o del bonus pater. Se trataba de un comportamiento reprobado por una regla de Derecho (como plantea MacCormarck) o de una conducta desfavorable en sí misma, según la indagación de Schipani, en la que resultaba esencial la evitabilidad y la posibilidad de desempeñar una conducta alternativa. La segunda nota es que en relación con la lex Aquilia, MacCormack señala que los juristas romanos tomaron en cuenta las habilidades y capacidades mentales para representarse el resultado dañoso y Schipani en términos similares indica que el sujeto debió haber estado en posición de comportarse de otra manera, tanto por causas extrínsecas como intrínsecas o psicológicas.

Con todo, la equiparación dista de ser plena, pues los métodos de ambos juristas inciden en el resultado de sus trabajos. Schipani realiza una indagación reconstructiva de los textos, buscando la aportación al problema de la culpa desde los orígenes literarios del término, hasta su desarrollo bizantino. Se trata de una reconstrucción histórica a partir de los textos, en los que Schipani va sosteniendo conclusiones parciales, relativas a cada período, pero de las que pueden extraerse, desde luego a título enteramente personal, al menos dos premisas generales. Primero, del trabajo de Schipani puede deducirse que el carácter originario de la culpa, como conducta reprobable en sí, con las características señaladas por el autor, permaneció mediante su desarrollo por los juristas republicanos y los clásicos e incluso los posclásicos. La evolución fue en el método, desde las aproximaciones más bien casuísticas a la culpa, en la que esta asume funciones polivalentes, pasando por los intentos de unificación dogmática de Gayo y hasta llegar al desarrollo de la culpa como elemento central del sistema de responsabilidad de la lex Aquilia. Si hemos entendido bien el estudio de Schipani, solo con los bizantinos habrá el intento de colocar exclusivamente la negligencia como centro del sistema.

Lo segundo es que el trabajo de Schipani, a nuestro juicio, es una categórica refutación del planteamiento objetivista, pues muestra que la culpa tiene un origen muy 
temprano y que su desarrollo no se correspondió con la mera afirmación del nexo de causalidad $^{46}$. Los textos van mostrándose como capas en las que se insertan las aportaciones de los juristas republicanos, clásicos, postclásicos y de la época justinianea. Cierto que en la construcción termina concluyendo que la culpa como negligencia se coloca como centro del sistema en la época bizantina, pero no opone esta conclusión -como lo hacen Arangio-Ruiz o Rotondi- a la circunstancia que los clásicos solo elaboraron un concepto objetivo.

Ahora bien, de acuerdo con la elaboración de ambos autores, la culpa supone una falla en la conducta (no en la voluntad). Ello supone que el sujeto no solo debe esforzarse por cumplir con el estándar social impuesto, sino que debe corregir sus propias imprecisiones naturales o su falta de preparación técnica y, en último término, evitar la práctica de los actos en los que carece de aptitud. Y por ello, la ignorancia también transita en el concepto de la culpa, porque el sujeto ignora, ha errado o falla en la previsión exigida ${ }^{47}$.

\section{El papel relacional de la culpa: sus vínculos con la causalidad}

A nuestro juicio, además, las deficiencias de análisis pueden quedar mejor suplidas si partiendo de los mismos presupuestos de estos autores, es decir, considerando que los juristas romanos no desarrollaron la culpa como negligencia-criterio de responsabilidad, sino como un instituto amplio de reproche individual de conductas, conectamos la función de la culpa especialmente en la causalidad. Ya hemos advertido el papel de la misma en la iniuria.

De modo que en nuestra óptica, la clave está en considerar el problema como un todo y no solamente algunos elementos aislados. Si la culpa es analizada en el contexto de un sistema y consideramos que esta (sea estricta o en un sentido amplio) correspondía o, más bien se desarrolló junto con las acciones decretales, la interpretación tendría que haberse encontrado en la ley y en la conciencia jurídica de los romanos. De esta manera, resulta evidente que con el tiempo todos los ámbitos de interpretación de la lex se fueron adecuando, pero el germen de todos ellos debió haber estado ya en la ley (así ya lo advirtió MacCormarck para la culpa) y consideramos que el papel de la culpa en la causalidad arroja luz sobre la funcionalidad de esta.

De este modo, intentamos defender que los elementos de la responsabilidad se encuentran interrelacionados hasta tal punto que no pueden distinguirse claramente uno de los otros, de modo que las diferenciaciones se hacen solo desde una perspectiva pedagógica. Entonces, en esta mutua compenetración es fácil asignarle el carácter funcional a la culpa: en la causalidad, resolviendo consecuentemente el otorgamiento

\footnotetext{
${ }^{46}$ De hecho, al estudiar los orígenes del instituto, el autor hace una expresa distinción entre culpa y causalidad. Véase Schipani, Responsabilità "Ex lege Aquilia”..., cit., pp. 124-125.

${ }^{47}$ Como indica Schipani, “Análisis...”, cit. p. 127: Pero si queremos escoger en modo unitario el significado de la culpa, incluyendo todas las facetas vistas, debemos entender que ella se refiere a una conducta voluntaria probibida sea por lo más de normas de prudencia, pericia, diligencia, sea también, más genéricamente, por otras disposiciones, cuya violación muestra la conducta reprochable.
} 
de la acción directa, útiles o in factum y, en sus vínculos con la iniuria, limitándola o ampliándola. En este artículo, solo podrán proponer las primeras líneas de los vínculos culpa-causalidad, en el desarrollo de la lex Aquilia ${ }^{48}$.

Con carácter general, MacCormack ha explicado las implicancias de la culpabilidad en la resolución de problemas de causalidad. El autor hace una sistematización, distinguiendo 3 grupos de casos en los cuales la culpabilidad era el factor relevante. De dichos casos, en el primer grupo pertenecen a situaciones de causa mediata y permiten distinguir cuando existía otorgamiento de actio directa y cuando, por el contrario, de actio in factum, como hemos analizado ${ }^{49}$. Con algunos matices, Zilioto, luego de estudiar varios casos de causalidad mediata, termina concluyendo que el elemento diferenciador del otorgamiento de acciones civiles versus in factum fue la conducta humana culposa. Cuando el inicio del curso causal podía identificarse con una conducta humana y esta era reprobable, se otorgaba una acción civil. Por el contrario, si dicha conducta no podía encontrarse como desencadenante del daño o bien la atención se fijaba en un elemento objetivo, factual y no en la culpa de quien provocaba mediatamente el daño, se concedía una actio in factum ${ }^{50}$.

A nuestro juicio, el principio tiene un carácter más general, presentándose la culpa como criterio que dilucidaba cuestiones causales en una amplia gama de casos, más allá del círculo de la causalidad mediata. La misma opinión sostiene MacCormack, quien indica que la culpabilidad fue un elemento que se presentaba en la decisión de los casos, tanto de causalidad mediata como en aquellos en que la vinculación podía ser identificada como mejor causa, pero no podía afirmarse todavía un vínculo de causalidad con el resultado. Por eso, a los dos grupos de casos que incorporan los supuestos de causalidad indirecta agrega un tercero, en el que la culpa estricta era la que permitía imputar el resultado al tercero ${ }^{51}$.

En esta línea se encuentra la opinión de Mela, contenida en D. 9, 2, $11 \mathrm{pr}^{52}$. El caso es interesante por varias razones. Primero, porque el curso causal no se inicia en los

${ }^{48}$ Para la cuestión del análisis causal, remitimos a nuestros trabajos Aedo Barrena, C. "Los requisitos de la lex Aquilia, con especial referencia al daño. Lectura desde las distintas teorías sobre el capítulo tercero", en Ius et Praxis 15, 1, 2009, p. 319 y Aedo Barrena, C., "La interpretación jurisprudencial extensiva a los verbos rectores de la lex Aquilia de damno", en Ius et Praxis 17, 1, 2011, pp. 9-16..

${ }^{49}$ Sobre los grupos de casos, MacCormack, G., "Juristic interpretation of the lex Aquilia", en AA.VV. Studi in onore di Cesare Sanfilippo, Giuffrè, Milán, 1982, t. I, pp. 271-283.

50 Zilioto, P., L'imputazione del danno aquiliano. Tra iniuria e damnum corpore datum, Cedam, Padova, 2000 , p. 139.

${ }^{51}$ MaCCORMACK, "Juristic Interpretation...", cit., p. 271; 277. Al respecto, señala: A problem frequently faced by the jurists concerned the relationship between someone's act and damage to someone else's property. Commonsense might suggest that the act could be represented as a cause of the damage. But it might also point to a difficult in that the act did not appear to be its sole cause. Other acts or other events might have contributed to the occurrence of the damage (...) In order to solve such problems and to establish a link between the act and the damage sufficient to justify the granting of an action legis Aquiliae or an action in factum the jurist had recourse to the notion of fault or to a particular variety of fault.

${ }^{52}$ Item Mela scribit, si, cum pila quidam luderent, vehementius quis pila percussa in tonsoris manus eam deiecerit et sic servi, quem tonsor habebat gula sit praecisa adiecto cultello: in quocumque eorum culpa sit, eum lege Aquilia teneri. Proculus in tonsore esse culpam: et sane si ibi tondebat ubi ex consuetudine Iudebatur vel ubi transitus frequens erat, est 
sujetos respecto de los cuales se analizan las implicancias de responsabilidad, como son el barbero y el esclavo, de modo que resulta un tanto sorprendente que Próculo no haya analizado la posible responsabilidad de los jugadores de pelota, pues esta situación era muy similar a los otros casos analizados por él mismo, en 7,2 (cuando otorga una actio in factum, tratándose de un supuesto de causalidad mediata) o en 11,5 (cuando confiere la acción directa, a pesar de la causalidad mediata, posiblemente, como hemos dicho, en virtud de la intencionalidad dañosa).

Digamos, en principio, que no estamos frente a una situación de causalidad indirecta, en el sentido que nuestro interés está puesto en el análisis de la responsabilidad de quien sirvió de instrumento material para la causación del daño. En esta situación lleva cierta razón Corbino, en el sentido que resulta evidente cómo en él tuvo importancia el medio empleado para causar el detrimento, pues si se hubiese provocado el perjuicio con un objeto inmaterial, es probable que los cuestionamientos sobre la responsabilidad hubiesen girado en torno a los jugadores de pelota. Aun así, a diferencia del pasaje D. $9,2,7,3$, en el que se excluyó la responsabilidad de quien había sido empujado, en el caso del barbero existía un plus que hacía radicar la responsabilidad en este y ese plus, nuevamente a nuestro juicio, fue la culpa, que hacía variar la cualificación de la causalidad.

Volviendo al caso, Mela simplemente se limitó a decir que debían responder cualquiera de los que resultaran responsables, analogando la situación a la responsabilidad de sujeto indeterminado de grupo determinado ${ }^{53}$. Sin embargo, el hecho que un jugador golpeara la pelota de manera más vehemente, no se le podía reprochar, por cuanto era probable que en el transcurso del juego la pelota volara a menudo fuera del campo del juego. ${ }^{54}$ Ello condujo a proponer otras posibles soluciones.

quod ei imputetur: quamvis nec illud male dicatur, si in loco periculoso sellam babenti tonsori se quis commiserit, ipsum de se queri debere (Escribe Mela que si varios jugasen a la pelota y uno, babiendo golpeado la pelota con más fuerza, la bubiese lanzado sobre la mano de un barbero de tal modo que a un esclavo al que el barbero estaba afeitando le fuera cortada la garganta con la navaja, queda obligado por la ley Aquilia cualquiera de los que fueran culpables. Próculo dice que la culpa está en el barbero, y ciertamente, si afeitaba allí donde era costumbre jugar o donde el tránsito era frecuente, hay motivo para imputarle la responsabilidad; aunque también se dice acertadamente que si alguien se confía a un barbero que tiene colocada la silla en un lugar peligroso, solo él tiene la culpa). Wacke, A., "Incidenti nello sport en el gioco in diritto romano e moderno", en Index 19, 1991, p. 363, ilustra las circunstancias que pudieron haber dado lugar a este caso. Según el autor, el pasaje supone que el barbero había colocado su puesto al aire libre, cerca del campo de juego, actividad que en realidad debió haber sido similar a un juego de hockey, en atención a las palabras utilizadas en el párrafo; además indica que no descarta que, precisamente por las características del negocio, los barberos circularan en lugares de gran atracción de público ofreciendo sus servicios, tal como hoy lo hacen los lustrabotas.

53 Por eso para MacCormack, “Aquilian Studies”, en SDHI 41, 1975, pp. 48-49, el breve pasaje de Mela, citado por Ulpiano, permite concluir que este autor no puso su atención en el problema de la culpa, sino que en el de la forma de la acción, pues parece haber aceptado que las circunstancias estaban comprendidas en el capítulo primero de la ley, de manera que las conexiones entre la conducta de los jugadores de pelota, el barbero y el daño no son tales como para excluir la actio legis Aquiliae.

${ }^{54}$ En este sentido, Wacke, cit., p. 364 y Castresana, A., Nuevas lecturas de la responsabilidad aquiliana, Ediciones Universidad de Salamanca, Salamanca, 2001, pp. 305-306. Como afirma Del Castillo Santana, M. S., Estudio sobre la casuística de las lesiones en la jurisprudencia romana, Dykinson, Madrid, 1994, p. 31, la ausencia de responsabilidad por parte del jugador o jugadores que lanzan la pelota se generalizó en Ulpiano, 
De este modo, en opinión de Ulpiano, la responsabilidad quedaba radicada en la propia víctima, pues argumenta que si confía en un barbero que tenía la silla en un lugar peligroso, solo él tiene la culpa. Desde luego, planteada así la cuestión, se trata de lo que modernamente se conoce como un supuesto de autopuesta en peligro o autolesión del bien propio, que han sido abordados especialmente en el Derecho penal, a propósito de la imputación objetiva.

Por último, la opinión que nos interesa destacar pertenece a Próculo, quien atribuye la causación del resultado al barbero, pero sujeto a condición de culpa. Sostiene Próculo que dicha culpa consistiría en el ejercicio de la actividad en condiciones inadecuadas o peligrosas. Así, aun cuando el barbero no inició el curso causal y su movimiento muscular constituyó un mero instrumento que causó el resultado, se le adjudica el resultado en razón de su conducta negligente y esta se hace radicar en el desempeño de su labor usual en lugares conocidamente peligrosos o inadecuados, de manera que era previsible que ocurriese un accidente y este pudo haberse evitado ${ }^{55}$.

Finalmente, este breve repaso de algunas decisiones, además de los señalados en el primer grupo, permite avanzar alguna hipótesis, aunque sea preliminar. Los textos estudiados demuestran a nuestro juicio que la culpabilidad y principalmente la culpa estricta, no fue indiferente para la solución de los problemas causales, sino que, por el contrario, constituyó un elemento normativo que restringía las valoraciones fácticas y en muchas ocasiones permitió dilucidar, frente a supuestos similares, el tipo de acción que se otorgaba.

De este modo, la cuestión que en la causalidad hay un análisis normativo y no solo fáctico no solo ha sido obra de la dogmática moderna. De momento, no parece adecuado detenerse a pensar si algunos de los elementos que se tratan a título de culpa merecen ubicarse en la causalidad o en el injusto, ni tampoco pretendemos que haya sido una discusión de los juristas romanos. Con este análisis solo queremos demostrar que gran parte de los problemas relativos a la configuración actual de los elementos de la responsabilidad civil han sido fruto de una lectura errónea de la forma en la que los juristas romanos las crearon e interpretaron originalmente, pues tal vez es posible separarlas

en D. 47, 10, 3, 3: Quare si quis per iocum percutiat, aut dum certat, iniuriarum non tenetur (Por lo cual, si golpease a otro por broma, o luchando, no está sujeto a la acción de injurias).

55 Según MacCormack, "Juristic interpretation...", cit., p. 278: In a sense one can say that the jurists reduced the question of causation to the question of fault and in effect held that the person (or persons) at fault caused the death and hence were liable under chapter one of the lex Aquilia. Para Buckland, The main institutions..., cit., p. 334, este caso establece el principio de que no se es responsable si el hecho no ha podido sobrevenir por su negligencia. Una opinión similar sostiene Núñez Paz, M. I., La responsabilidad de los médicos en Derecho romano, Gráficas Apel, Gijón, 1996, p. 122, en un supuesto totalmente distinto, como es el caso de la comadrona que otorga una medicina a la mujer esclava, contenida en D. 9, 2, 9pr. Según la autora: La interpretación pretoria y jurisprudencial permiten asi que se siga ampliando el marco de conductas susceptibles de ser encajadas en la Lex Aquilia, siquiera indirectamente, como supuestos de responsabilidad por culpa. La culpa se contempla no tanto desde el punto de vista subjetivo como desde la más pura relación causal. Es suficiente probar que como consecuencia del suministro del medicamento se produce la muerte de la esclava. Con todo, como indica MacCormack, "Aquilian Studies...", cit., pp. 48-49, la corta decisión de Próculo citada por Ulpiano, presenta dos puntos de dificultad: en primer lugar, no queda claro si la razón señalada por Ulpiano fue la única indicada por Próculo y, en segundo lugar, no se sabe con certeza si Próculo efectivamente otorgó la actio legis o, por el contrario, una actio in factum. 
de modo teórico, pero en la decisión del caso, que es a lo que se atuvieron los juristas de ese tiempo, resulta imposible desligar los aspectos causales de los culpabilísticos.

Además, hay otra cuestión que nos parece significativa. Del estudio de los casos en los que se utiliza la culpa para resolver las cuestiones causales puede extraerse un elemento común: en todas ellas el análisis normativo o culpabilístico se efectúa antes de conectar materialmente una conducta con un resultado. La decisión del barbero nos parece extraordinariamente clara, pues el sujeto responsable no inicia el curso causal, pero se le imputa el resultado y no se le trata como un mero instrumento empleado por el jugador de pelota que lanza con fuerza el balón. Al afeitar en un lugar reconocidamente peligroso, de acuerdo con el tipo de actividad, el barbero sabía o debía conocer que desarrollar su actividad en dicho lugar podía desencadenar un resultado pernicioso para el esclavo, pudo haberlo previsto y evitado y por eso se le hace responsable del perjuicio. Si mentalmente nos situamos en este contexto, resulta claro que afirmar la responsabilidad del barbero supone razonar en términos de culpa o exclusivamente normativos, aunque el pensamiento disfrace dicha conexión con la causalidad.

Un supuesto totalmente distinto, pero en la que la culpa juega el mismo rol, es el caso del carretero, en 27,33 , pues en dicha circunstancia es el sujeto responsable el que inicia el curso causal, aunque no hay un daño inferido directamente. Al igual que el anterior, el jurista que resuelve el problema hace un análisis previo de la culpabilidad, antes que averiguar si puede encontrarse una conexión material entre la conducta consistente en ubicar ciertas piedras en la carreta y los daños ocasionados como consecuencia de su caída.

Esta manera de proceder, examinando la culpa antes que la causalidad o resolviendo los problemas de la causalidad mediante la culpa, según los casos, parece haber sido la regla, pues como hemos dicho, los juristas romanos actuaban sin los esquemas que inevitablemente los conceptos dogmáticos han introducido en los juristas modernos. No se preocuparon ni de las categorías - por eso parece más razonable entender la culpa como equivalente a la falta y no como negligencia- ni estructuraron el juicio de responsabilidad en compartimentos, exigiendo la comprobación de un nexo causal material o físico, para luego indagar la existencia de la culpa, prejuicio que acarrea inevitablemente la ciencia jurídica desde el positivismo científico y filosófico y desde la separación escrupulosa entre los aspectos subjetivos y objetivos de la realidad.

\section{BIBLIOGRAFÍA}

Aedo Barrena, C. "Los requisitos de la lex Aquilia, con especial referencia al daño. Lecturas desde las distintas teorías sobre el capítulo tercero”, en Ius et Praxis 15, 1, 2009.

Aedo Barrena, C., Culpa aquiliana: una conjunción de aspectos históricos, filosóficos y dogmáticos, Universidad de Deusto, Bilbao, 2010.

Aedo Barrena, C., "La interpretación jurisprudencial extensiva a los verbos rectores de la lex Aquilia de damno", en Ius et Praxis 17, 1, 2011.

Albanese, Bernardo, "Recensioni critiche a Valditara. Superamento dell'aestimatio rei nella valutazione del danno aquiliano ed estensione della tutela ai non domini”, en IURA 43, 1992.

Arangio-Ruiz, V., Responsabilità conttratuale in Diritto romano, Editricce Eugenio Jovene, reimpresión $2^{a}$ edición, Napoli, 1958. 
BeINART, B., "The relationship of iniuria and culpa in the lex Aquilia", en AA.VV. Studi in onore di Vicenzo Arangio-Ruiz, Jovene Editore, Napoli, 1964.

Betti, E., Istituzioni di Diritto Romano, Cedam, Padova, 1962.

Bonfante, P., Instituciones de Derecho Romano, trad. de la $8^{a}$ edición italiana por Luis Bacci y Andres Larrosa, revisada por Fernando Campuzano Horma, Reus, $2^{\text {a }}$ edición, Madrid, 1959.

BuCKLAND, W.W, The main institutions of Roman private law, Cambridge University Press, London, 1931.

Burdese, A., Manuale di Diritto Privato Romano, UTET, 4a edición, Torino, 1993.

Cannata, C. A., Ricerche sulla responsabilità contrattuale nel Diritto romano, Guiffrè, Milano, 1966, t. I.

Cannata, C.A., Per lo studio della responsabilità per colpa nel diritto romano classico, La Giolardica, Milano, 1969.

Castresana, A., Nuevas lecturas de la responsabilidad aquiliana, Ediciones Universidad de Salamanca, Salamanca, 2001.

Daube, D., "On the use of the term damnum", en AA.VV. Studi in onore di Siro Solazzi, Casa Editriche Eugenio Jovene, Napoli, 1948.

Daube, D., Roman law. Linguistic, social and philosophical aspects, Edinburg University Press, Edinburg, 1969.

Del Castillo Santana, M. S., Estudio sobre la casuística de las lesiones en la jurisprudencia romana, Dykinson, Madrid, 1994.

D’Ors, A., Derecho Privado Romano, Ediciones Universidad de Navarra, 9ª edición, Pamplona, 1997.

Ferrini, C., Diritto Penale Romano, L' Erma di Bretschneider, Roma, 1976.

Guarino, A., Diritto Privato Romano, Editore Jovene, Napoli, 1997.

Guzmán Brito, A., Derecho Privado Romano, LegalPublishing-Thompson Reuters, $2^{a}$ edición, Santiago, 2013, t. II.

MAC Cormack, G., "Culpa”, en SDHI 38, 1972.

MAC Cormack, G., "Aquilian culpa”, en Alan Watson (editor), Daube Noster. Essays in Legal History for David Daube, Scottisch Academic Press, Edinburgh, 1974.

MAC Cormack, “Aquilian Studies”, en SDHI 41, 1975.

MAC Cormack, G., "Juristic interpretation of the lex Aquilia", en AA.VV. Studi in onore di Cesare Sanfilippo, Giuffrè, Milano, 1982, t. I.

MAC Cormack, G., "Juristic use of the term Dolus: Contract”, en ZSS 100, 1983.

MAC Cormack, G., "'Dolus', 'Culpa' and 'Diligentia'. Criteria of Liability or Content of Obligations", en Index 22, 1994.

MaRTínez Sarrión, A., Las raíces romanas de la responsabilidad por culpa, Bosch, Barcelona, 1993.

MARTON, G., "Un essai de reconstruction du développement probable du système classique romain de responsabilité civile", en AA.VV. Mélanges Fernand de Visscher, RIDA, Bruselas, 1949, t. II.

NúÑez Paz, M. I., La responsabilidad de los médicos en Derecho romano, Gráficas Apel, Gijón, 1996.

Perrin, B., "Le caractère subjectif de l'iniuria aquilienne à l'époque classique", en Edoardo Volterra (a cura di), Studi in onore di Pietro de Francisci, Guiffrè, Milano, 1956, vol. IV.

Pugliese, G., Istituzioni di Diritto Romano, Giappichelli, $3^{a}$ edición, Torino, 1991.

Pugsley, D., "On the lex Aquilia and culpa", en TR 50, 1982.

Robaye, R., "Responsabilité objective ou subjective en droit romain”, en TR 18, 1990.

Rodríguez Devesa, J. M., Derecho Penal. Parte General, Dykinson, 16ª edición, Madrid, 1990.

Rotondi, G., "Dalla Lex Aquilia all art. 1151 Cod. Civ. Ricerche storico-dogmatiche", en Rivista del Diritto Commerciale, vol. XIV, 1916.

Schipani, S., Responsabilità "Ex lege Aquilia". Criteri di imputazione e problema della "culpa", Giappichelli, Torino, 1969. 
Schipani, S., "Pluralità di prospettive e ruolo della culpa come criterio elaborato dalla scienza del diritto nell'interpretazione della lex Aquilia”, en Studia Iuridica 12, 1985.

Schipani, S., “Análisis de la culpa en Justiniano 4,3”, en Aída Kemelmajer de Carlucci y Jesús Alberto Bueres (directores), Responsabilidad por daños en el Tercer Milenio. Homenaje al profesor Doctor Atilio Aníbal Alterini, Abeledo Perrot, Buenos Aires, 1997.

SCHIPANi, S., "Dalla lex Aquilia a D. 9: prospesttive sistematiche del Diritto romano e problema della responsabilità extracontrattuale", en AA.VV, Colloqui in ricordo di Michele Giogianni, Napoli, 2007.

SCHIPANI, S., "Interpretazione della lex Aquilia nei giuristi replicani e il problema della culpa", en el mismo, Contributi romanistici al sistema della responsabilità extraconttratuale, Giappichelli, Torino, 2009.

SCHIPANI, S., Contributi romanistici al sistema della responsabilità extracontrattuale, Giappichelli, Torino, 2009.

Talamanca, M., Istituzioni di Diritto Romano, Giuffrè, Milano, 1990.

VAZNY, G., "Svolgimento della responsabilità per colpa nel diritto romano", en AA.VV. Acta Congressus Iuridici Internationalis, Intituti Utriusque Iuris, Roma, 1935.

VISKY, K., "La responsabilité dans le droit romain á la fin de la République", en AA.VV., Mélanges Fernand de Visscher, RIDA, Bruselas, 1949, t. II.

Voci, P., "L'estensione dell'obbligo di risarcire il danno nell diritto romano classico", en AA.VV. Scritti in onore di Contardo Ferrini pubblicati in occasione della sua beatificazione, Sociedad Editriche Vita e pensiero, Milano, 1934, vol. II.

Voci, P., Istitutizioni di Diritto Romano, Giuffrè, Milano, 1954.

VocI, P., “'Diligentia', 'Custodia', 'Culpa', I dati fundamentali”, en SDHI 56, 1990.

Volterra, E., Instituciones de Derecho Privado Romano, trad. de Jesús Daza Martínez, Civitas, reimpresión $1^{\text {a }}$ edición, Madrid, 1988.

WaCKe, A., "Incidenti nello sport en el gioco in diritto romano e moderno”, en Index 19, 1991.

Watson, A., The law of obligations in the later Roman Republic, Clarendon Press, London, 1965.

WAtson, A., "D. 7. 1. 13. 2 (Ulpian 18 ad Sab.): the lex Aquilia and decretal actions", en IURA $17,1966$.

Watson, A., Roman Private Law around 200 B.C., Edinburgh University Press, Edinburgh, s.d.

Zilioto, P., L'imputazione del danno aquiliano. Tra iniuria e damnum corpore datum, Cedam, Padova, 2000.

Zimmermann, R., The Law of Obligations. Roman Foundations of the Civilian Tradition, Oxford, 1996. 